\title{
Historia, Saberes y Prácticas: Un Ensayo Sobre el Desarrollo de las Comunidades Alfareras del Norte Semiárido Chileno
}

\author{
Histories, Knowledges and Practices: An Essay About the \\ Development of Pottery Communities of the Semiarid North of Chile
}

Andrés Troncoso ${ }^{\mathrm{y}}$ y Daniel Pavlovic ${ }^{\mathrm{II}}$

\begin{abstract}
RESUMEN
El periodo Alfarero del Norte Semiárido Chileno se ha caracterizado por la existencia de una secuencia histórica-cultural homogénea construida a partir de la definición de entidades culturales expresadas en conjuntos materiales y momentos cronológicos especificos. En este trabajo se entrega una reevaluación de tal secuencia, proponiendo la existencia de tres sectores de desarrollo diferencial en la zona, los que presentan dinámicas y formas de vida distintos, no obstante la homogeneidad que se observa en ciertos elementos de cultura material. Reconocida esta heterogeneidad, se sugiere una interpretación sobre su razón de ser a partir del reconocimiento de procesos históricos locales y la expansión de sistemas simbólicos que se materializan en saberes y prácticas particulares a lo largo de este territorio.
\end{abstract}

Palabras Claves: Norte Semiárido, Periodo Alfarero, Saberes, Prácticas, Cosmovisión

\begin{abstract}
Cultural history of Pottery Period in the Semiarid North of Chile have been characterized through an homogeneus sequence in which particular cultural entities was defining, each one having specific material culture and temporal moments. In this paper, we rethink this sequence through a new revision of archaeological contexts of this region. Several differences between valleys are identified through this revision, which allows suggests three diferents sectors in Semiarid North of Chile, each one as an own way of life and dwelling. An interpretative hipotesys is proposed to understand the homogeneity and heterogeneity identified in the region in the Pottery period. Historical development, material conditions of existence and the expansion of symbolic systems, all which are materialized in knowledges and practices, are proposed as a mechanism to understand this reality.
\end{abstract}

Key Words: Semiarid North, Pottery Period, Knowledges, Practices, Cosmovision

\footnotetext{
Departamento de Antropología, Universidad de Chile. Av. Ignacio Carrera Pinto 1045, Nuuñoa, Santiago:

Correo-e: atroncos@uchile.cl

ii Orolonco Consultores. Correo-e: Daniel.pavlovic@gmail.com

Recibido: 11 de enero de 2012. Revisado: 23 de julio de 2012. Aceptado: 2 de mayo de 2013.
} 


\section{INTRODUCCIÓN}

La conformación de una historia cultural para el período prehispánico del Norte Semiárido (en adelante NSA), en especial para el período alfarero, se remonta a mediados del siglo XX cuando los trabajos de Latcham (1928, 1937), y las reformulaciones efectuadas por Cornely (1956), crearon el esquema básico de desarrollo temporal y cultural de las comunidades que habitaron este territorio. Sobre ella, posteriormente, autores como Montané y Niemeyer (1960), Iribarren (1969), Montané (1969) y Ampuero (1978, Ampuero y Rivera 1972-73), efectuaron importantes ajustes que dieron forma a los esquemas manejados en la actualidad y reproducidos en las últimas síntesis al respecto (Ampuero 1989, Castillo 1989, Niemeyer et al. 1989). No obstante los años traspasados entre unas y otras proposiciones, todas ellas descansaron en un marco teórico similar, de corte histórico cultural y priorizando dos premisas centrales: i) la asociación tipologia=cronología, ii) el difusionismo como mecanismo explicador del cambio.

La secuencia resultante consistió de un conjunto de períodos cerrados, caracterizados por la presencia de un determinado grupo cultural, materializado en una tipología de cultura material y prácticas funerarias, y distribuidos en un rango temporal específico (ver p.e. Ampuero 1989, Castillo 1989, Niemeyer et al. 1989). Ello originó un período alfarero uniforme a lo largo de todo el NSA, representado por una sucesión de grupos culturales: Complejo Cultural El Molle, Complejo Cultural Las Ánimas y Cultura Diaguita Chilena dividida en sus fases I, II y III; cada una con un rango de extensión temporal definida y sin mayores traslapes entre si, salvo en el último caso (Diaguita-Diaguita Inca).

Sin embargo, conocidas en la zona, más la revisión de la bibliografía existente, pretende efectuar una reevaluación del período Alfarero en el NSA, en pos de presentar una nueva propuesta para su entendimiento basada en reconocer la relevancia de los sistemas simbólicos, las trayectorias históricas y el papel significativo de la cultura material ${ }^{1}$.

Específicamente, se plantea que este período presenta una amplia variabilidad espacial, teniendo sus desarrollos diferentes niveles de complejidad, por lo que bajo una supuesta homogeneidad en elementos particulares de la cultura material (p.e. cerámica) se dan diferencias significativas en las formas de vida de estas poblaciones y sus formas de habitar el mundo. Estas diferencias se relacionarían con los desarrollos históricos particulares de cada valle y se extenderían a lo largo de todo el período alfarero. las transformaciones en los marcos teóricos y metodológicos acaecidos en los últimos ańos, sumado al estudio intensivo de nuevos espacios, en particular 
los valles de Copiapó y Choapa, han entregado una batería de nuevos datos que permiten complejizar el entendimiento del período alfarero en este territorio. No obstante ello, aún no se ha desarrollado una reevaluación mayor de los postulados básicos que organizan este período, ni una integración de la información recogida décadas atrás. Es este último punto el objetivo del presente ensayo, el que a partir de la incorporación de las nuevas evidencias

Se propone que la presencia de estos elementos materiales más que dar cuenta de una homogeneidad poblacional, sugieren la existencia de elementos ideacionales compartidos, los que se reproducirían en un conjunto de saberes y prácticas específicos que se expandirían por el NSA. Estos serían apropiados por las comunidades de los distintos valles de manera diferencial y en relación más bien con sus devenires históricos que con un proceso de homogeneización.La dinámica de esta situación permitiría reconocer al interior del NSA la presencia de tres sectores diferenciados y con dinámicas distintas: Copiapó-Huasco, Elqui-Limarí y Combarbalá-Choapa (Figura 1).

Para avalar esta proposición, efectuamos una discusión de las evidencias materiales para cada valle, la que antes que centrarse en temas tipológicos, abordará relaciones de presencia/ausencia en el registro arqueológico en pos de acercarnos a sus implicancias sociales. A partir de ellas, proponemos una reformulación para los diferentes períodos.

Sabemos que la información arqueológica disponible en la actualidad es muy desigual para cada uno de estos espacios. Sin embargo, es verdad también que la secuencia arqueológica ha sido construida a partir de tales datos, por lo que pensamos que es lógico y justificable intentar realizar una nueva relectura de ellos y que, no obstante los sesgos de la investigación existentes, la alta cantidad de sitios arqueológicos excavados, así como las prospecciones que se han realizado durante décadas en el NSA permiten pensar que las diferencias que aquí plantearemos son significativas.

La desigual información que se dispone para cada valle se refrenda en sus historias de investigación particular. Mientras en el valle de Copiapó hay un extenso desarrollo de trabajos arqueológicos producto de rescates y estudios amplios fundados en proyectos Fondecyt, Huasco y Elqui cuentan más bien con excavaciones de cementerios y rescates arqueológicos, muchas de ellas realizadas en el período de 1940 a 1970 (p.e. Cornely 1956, Biskupovic 1985, Biskupovic y Ampuero 1991, Iribarren y Niemeyer 1956) y con una mayor intensidad en Elqui. Son posiblemente los trabajos de Stehberg (1995), interesado en identificar y caracterizar asentamientos incaicos asociados a la red vial cordillerana, los que se han basado en una escala de trabajo más amplia. 


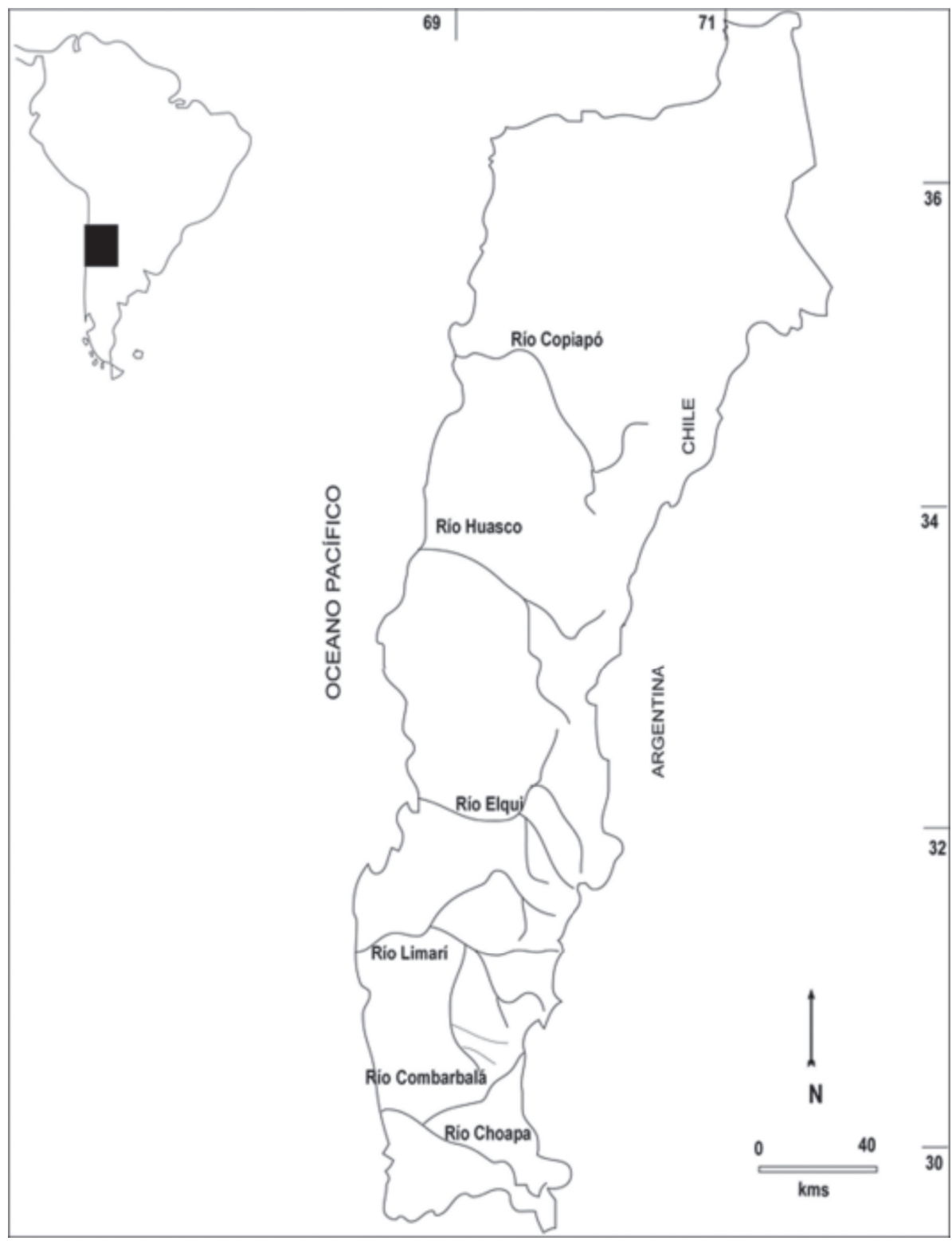

Figura 1: Mapa del norte semiárido chileno, con indicación de sus principales valles.

Figure 1: Map of Semiarid Norh of Chile with indication of major valleys.

Esta situación es en cierta medida compartida por el valle de Limarí, aunque acá se encuentra también la excavación de asentamientos habitacionales y su datación absoluta (p.e. Ampuero y Rivera 1964, 1971), así como recientes reevaluaciones de antiguos contextos y dataciones de piezas (p.e. Cantarutti 2002, Suárez et al. 1989). 
Una situación parecida ocurre con Combarbalá, donde a las inspecciones visuales, caracterización de piezas arqueológicas y rescate de tumbas, se suman trabajos recientes publicados con resultados relativos a prospecciones sistemáticas, excavaciones de sitios habitacionales y dataciones absolutas de contextos (Méndez et al. 2004, Méndez y Jackson 2008, Méndez et al. 2009).

Finalmente, el valle del Choapa presenta una realidad completamente distinta a todas las anteriores, debido a la intensidad de la investigación de las últimas décadas producto de proyectos de investigación e Impacto Ambiental que han permitido intervenir una importante cantidad de asentamientos de distintas funcionalidad y obtener un amplio set de fechados absolutos.

\section{REeVAluando el PERÍOdo ALFARERO TEMPRANO: COMPLEJO Cultural El Molle}

La excavación de seis cementerios de la localidad de El Molle, ubicada en el valle de Elqui, permitió reconocer a Cornely $(1956,1958)$, un conjunto de enterratorios con una cultura material completamente diferente a la Diaguita, caracterizada por alfarería monocroma con decoraciones incisas, tembetás y pipas de piedra, entre otros. Su reconocimiento como una entidad diferente a lo Diaguita, lo llevó a bautizarla como El Molle, siguiendo la sugerencia de Ricardo Latcham (Cornely 1958) y usando el criterio de sitiotipo.

El posterior reconocimiento de esta ergología en otros sectores del NSA sentó la base para definir al Complejo Cultural El Molle como representante poblacional del período Alfarero Temprano (en adelante PAT), extendiéndose cronológicamente entre los años 0-800 d.C. (Niemeyer et al. 1989) y espacialmente entre los valles de Copiapó y Choapa, no obstante la presencia de una serie de particularidades en este último producto de su cercanía con Chile central (Castillo 1991, Niemeyer et al. 1989), que llevaron a no incorporarlo directamente dentro de lo Molle.

Su origen articularía directamente con el período Arcaico Tardío, a partir de la fase Quebrada Honda (Ampuero 1972-73, Castillo 1986, Kusmanic y Castillo 1986, Niemeyer et al. 1989, Schiapacasse y Niemeyer 1986), la que tendría rasgos similares a los del Complejo Cultural El Molle, a excepción de la presencia de alfarería; reconociéndose una relación estratigráfica de superposición entre uno y otro componente en los sitios 
de Valle El Encanto y San Pedro Viejo de Pichasca (Ampuero 1972-73, Ampuero y Rivera 1964, 1969, 1971).

Aunque las razones del cambio de un componente a otro no es del todo claro, algunos autores proponen el ingreso de grupos foráneos que se fusionarían con las poblaciones locales (p.e. Ampuero 1972-73, Cornely 1956, Kuzmanic y Castillo 1986, Rivera y Ampuero 1969, Munizaga $1972-$ 73), mientras otros sugieren hablar de procesos co-tradicionales con la vertiente oriental de Los Andes, en particular con los desarrollos Cienaga, Condorhuasi y Candelaria (Ampuero e Hidalgo 1975).

Independientemente de la lógica del cambio, este modelo tradicional ha reconocido en la conformación del Complejo Cultural El Molle a la primera población agroganadera y sedentaria del NSA (p.e. Castillo 1991, Iribarren 1973, Niemeyer et al. 1989), la que se encontraría uniformizada por una serie de datos contextuales, donde primaría a grosso modo la trilogía tembetás, pipas y alfarería monocroma. Sin embargo, tras esa homogeneidad, y como ya fue avanzado por una serie de autores (Castillo 1991, Niemeyer et al. 1989), se reconocen un conjunto de diferencias entre los distintos valles que procedemos a discutir.

Como se observa en la tabla 1, en lo que hace referencia a los asentamientos, se da una diferencia entre Copiapó y todos los valles más meridionales, la que se basa en la oposición presencia / ausencia de aldeas, pues descontando el Huasco donde no hay mayor investigación al respecto, desde Elqui no se reconocen aldeas, sino reparos rocosos o sitios a cielo abierto asociados en ocasiones a piedras tacitas y/o arte rupestre. 


\begin{tabular}{|c|c|c|c|c|c|c|}
\hline & $\begin{array}{l}\text { Tipos de } \\
\text { Asentamientos }\end{array}$ & $\begin{array}{l}\text { Tipos de } \\
\text { Enterratorios }\end{array}$ & \begin{tabular}{|l|} 
Tipos de \\
Camélidos
\end{tabular} & $\begin{array}{l}\text { Tipos de } \\
\text { Cultígenos }\end{array}$ & $\begin{array}{l}\text { Instrumentos } \\
\text { Agrícolas }\end{array}$ & \begin{tabular}{|l|} 
Referencias \\
Bibliográficas
\end{tabular} \\
\hline \begin{tabular}{|l|} 
Valle de \\
Copiapó
\end{tabular} & $\begin{array}{l}\text { Aldeas } \\
\text { Reparos } \\
\text { Rocosos }\end{array}$ & $\begin{array}{l}\text { Túmulos } \\
\text { Simples }\end{array}$ & Llama & $\begin{array}{l}\text { Maíz } \\
\text { Poroto } \\
\text { Cucurbitá- } \\
\text { ceas }\end{array}$ & $\begin{array}{l}\text { Palas } \\
\text { Molienda }\end{array}$ & $\begin{array}{l}\text { Niemeyer } 1997 \mathrm{~b} \\
\text { Niemeyer } \text { et al. } \\
1989\end{array}$ \\
\hline $\begin{array}{l}\text { Valle de } \\
\text { Huasco }\end{array}$ & Sin información & Túmulos & $\begin{array}{l}\text { Sin infor- } \\
\text { mación }\end{array}$ & $\begin{array}{l}\text { Sin } \\
\text { información }\end{array}$ & $\begin{array}{l}\text { Palas } \\
\text { Molienda }\end{array}$ & \begin{tabular}{|l} 
Kuzmanic 1988 \\
Niemeyer et al. \\
1989 \\
Niemeyer 1979
\end{tabular} \\
\hline $\begin{array}{l}\text { Valle de } \\
\text { Elqui }\end{array}$ & $\begin{array}{l}\text { Sitios a cielo } \\
\text { abierto }\end{array}$ & $\begin{array}{l}\text { Ruedos de } \\
\text { piedra con } \\
\text { arquitectura } \\
\text { interior }\end{array}$ & $\begin{array}{l}\text { Sin infor- } \\
\text { mación }\end{array}$ & Poroto & $\begin{array}{l}\text { Escasas Palas } \\
\text { Molienda }\end{array}$ & $\begin{array}{l}\text { Castillo } 1986 \\
\text { Cornely } 1956 \\
\text { Niemeyer } \text { et al. } \\
1989\end{array}$ \\
\hline $\begin{array}{l}\text { Valle de } \\
\text { Limarí }\end{array}$ & $\begin{array}{l}\text { Sitios a cielo } \\
\text { abierto } \\
\text { Reparos rocosos }\end{array}$ & $\begin{array}{l}\text { Ruedos de } \\
\text { piedra con } \\
\text { arquitectura } \\
\text { interior }\end{array}$ & $\begin{array}{l}\text { Sin infor- } \\
\text { mación }\end{array}$ & $\begin{array}{l}\text { Maíz } \\
\text { Poroto }\end{array}$ & Molienda & \begin{tabular}{|l|} 
Ampuero y \\
Rivera 1969, \\
1971 \\
Cornely 1956 \\
Iribarren 1958 \\
Niemeyer et al. \\
1989
\end{tabular} \\
\hline $\begin{array}{l}\text { Valle de } \\
\text { Com- } \\
\text { barbalá }\end{array}$ & $\begin{array}{l}\text { Sitios a cielo } \\
\text { abierto } \\
\text { Reparos rocosos }\end{array}$ & Simples & Guanaco & $\begin{array}{l}\text { No Maíz } \\
\text { No Poroto }\end{array}$ & Molienda & \begin{tabular}{|l} 
Méndez y \\
Jackson 2008 \\
Méndez et al. \\
2008 \\
Iribarren 1973 \\
Rivera y Cobo \\
1996
\end{tabular} \\
\hline $\begin{array}{l}\text { Valle de } \\
\text { Choapa }\end{array}$ & $\begin{array}{l}\text { Sitios a cielo } \\
\text { abierto }\end{array}$ & Simples & Guanaco & Quinoa & Molienda & \begin{tabular}{|l|} 
Pavlovic 2004 \\
Belmar y Quiroz \\
2002,2003
\end{tabular} \\
\hline
\end{tabular}

Tabla 1: Características de los contextos arqueológicos del periodo Alfarero Temprano en el Norte Semiárido.

Table 1: Characteristics of archaeological contexts of Early Pottery period in the Semiarid North of Chile

Tal diferenciación se complejiza aún más si consideramos las prácticas funerarias en uno y otro valle (Tabla 1). En este caso, se puede plantear una división tripartita entre Copiapó/Huasco; Elqui/Limarí y Combarbalá/Choapa. Para la primera zona, prima en el patrón mortuorio los enterramientos en túmulos con relleno de material interpretado como basura doméstica, o bien con rocas (Niemeyer 1979, 1997a, Niemeyer et al. 1989, Gallardo 1990). En contraposición, el segundo sector carece de túmulos, encontrándose las tumbas señalizadas superficialmente por ruedos de piedras, pero con arquitectura interna compuesta de troncos y piedras (Cornely 1956, Iribarren 1958, Niemeyer et al. 1989). Finalmente, para la última área sólo se han descrito tumbas simples, sin señalización exterior, ni arquitectura funeraria interna (Castillo 1991, Iribarren 1973). 
Al respecto, debemos hacer notar que si bien Méndez y Jackson (2008), indican que Iribarren (1973), describe tumbas con señalizacion para Combarbalá (las que deberían corresponder al sitio La Escondida), la verdad es que el autor menciona que "las sepulturas no conservaban ningún elemento exterior que las identificaran" (Iribarren 1973: 61), deduciendo que unas piedras de gran tamaño que estaban en el lugar podrían ser parte de una señalización. Consideramos tal asignación al menos dudosa, pues por un lado, hay una ausencia de un elemento central a este tipo de enterratorio: su arquitectura funeraria interna y por otro, el contexto del sitio sugiere la presencia de una ocupación de tiempos Tardíos (Diaguita Incaica) (Iribarren 1973), que complejiza una asignación simple de las rocas a una señalización de tumba.

Mientras los asentamientos sugieren una diferencia entre Copiapó y los valles de más al Sur, los patrones funerarios ratifican y amplían tal diferenciación. Si consideramos los postulados de Criado (1993, 2000), relativos a la relación entre visibilidad y racionalidad, proponemos que las diferencias en las características de los contextos funerarios refieren a divergencias en las estrategias de visibilización implementadas por estas poblaciones, las que en última instancia, indican distintas formas de relacionarse con la naturaleza y estrategias diferenciales de construcción social del espacio.

Para el sector de Copiapó-Huasco las prácticas funerarias implementan una estrategia de monumentalización a partir de la presencia de túmulos, para Elqui-Limarí, la existencia de señalizaciones exteriores en la tumba implementan una estrategia de exhibición, dado el carácter no monumental de los ruedos de piedra. Combarbalá-Choapa, finalmente, se remiten más bien a una de inhibición, dada por la ausencia de algún tipo de señalización superficial. Estas diferencias espaciales y de visibilidad se ratificarían con las divergencias apreciables en la información actualmente disponible sobre el patrón de asentamiento entre los desarrollos de Copiapó y las zonas más sureñas, donde la escasa investigación en Huasco no permite reconocer a ciencia cierta la presencia o ausencia de aldeas.

Estos datos, por tanto, permiten sugerir que para el PAT en el NSA nos encontramos, al menos con áreas que presentan modos de habitar divergentes entre si. Estas diferencias entre valles se aumentan si consideramos otros dos aspectos: el registro bioarqueológico y los instrumentos agrícolas.

Aunque no existen detallados análisis zooarqueológicos para el área de estudio, la presencia de posibles corrales (Niemeyer et al. 1989) y el 
análisis de las muestras del sitio Las Terneras 1 (Labarca 2008), indican para Copiapó la presencia de camélidos domésticados, Llama (Lama Glama). En contraposición, para Combarbalá y Choapa se reconoce la presencia únicamente de camélidos silvestres, Guanaco (Lama Guanicoe) (Becker 2004, Méndez y Jackson 2008). Proponemos que para el sector central del NSA posiblemente se repita la situación del área meridional, dada la ausencia de algún indicador de domesticación de camélidos, como pueden ser corrales, idea que se potenciará cuando discutamos los contextos del período Medio.

$\mathrm{Al}$ respecto, uno de los criterios principales que se utilizaron para la asociación de Molle con la ganadería no fue sólo la aparición de la cerámica y el sedentarismo, situación que sabemos hoy no es una ecuación directa (ver p.e. Cornejo y Sanhueza 2003, Eerkens 2003, Politis et al. 2001.), sino también la importante presencia de camélidos en el arte rupestre local (p.e. Castillo 1986, Niemeyer et al. 1989, Niemeyer y Ballereau 1998). Sin embargo, este argumento presenta importantes problemas, no sólo por su circularidad (dado que los grupos Molles son ganaderos, representan camélidos; la representación de camélidos implica que los grupos Molle eran ganaderos), sino también porque, por un lado, reevaluaciones en el arte rupestre de diferentes sectores del NSA están poniendo en duda la exclusividad de su asignación al período Alfarero Temprano (p.e. Cabello 2005, 2011; Jackson et al. 2002, Ballereau y Niemeyer 1998, Troncoso 1999, Troncoso et al. 2008a). Por otro, si bien es real que hay una gran cantidad de camélidos grabados en las rocas del NSA, el único trabajo orientado a identificar el tipo de camélido presente en los petroglifos de la zona muestra las complicaciones de segregar entre Guanaco y Llama y sugiere que los últimos son más recurrentes en contextos Tardíos (Troncoso 2012), situación que confirma apreciaciones previas (Jackson 2005, Troncoso 2009).

La diferenciación entre sectores se refuerza al revisar las características de las industrias líticas relacionadas con labores agrícolas. Para Copiapó/ Huasco hay referencias a un importante número de palas agrícolas (Niemeyer 1997a), instrumentos que son escasos en los contextos de Elqui/ Limarí (Niemeyer et al. 1989), y sin registro en Combarbalá/Choapa (Iribarren 1973, Méndez y Jackson 2008, Méndez et al. 2009), no obstante los abundantes estudios en este último sector.

Esta diferencia se expresa también en los pocos contextos arqueobotánicos conocidos, donde para Copiapó hay referencias de maíz (Zea mays), poroto (Phaseolus vulgaris) y cucurbitáceas entre otros (Niemeyer 1997); mientras que para Elqui/Limarí se reconoce básicamente poroto y 
unas pocas evidencias de maíz en San Pedro Viejo de Pichasca (Castillo 1986, Ampuero y Rivera 1971). Para Combarbalá no hay registro ni de poroto, ni de maíz (Méndez et al. 2008), mientras que en Choapa básicamente se han recuperado restos de quinoa (Chenopodium quinua) (Belmar y Quiroz 2002, 2003, Pavlovic 2004).

Estas diferencias que se expresan en distintos niveles del registro arqueológicos (patrón de asentamiento, prácticas funerarias, registro bioarqueológico e instrumentos agrícolas) nos permite plantear que el PAT en el NSA engloba tres situaciones completamente diferentes, las que se asocian con formas de vida y modos de habitar divergentes entre si. Reconocemos un primer sector correspondiente a Copiapó/Huasco, posiblemente caracterizado por una asentamientos agrupados (aldeas) con prácticas de agricultura y pastoreo de camélidos; un segundo sector, Elqui/ Limarí, donde hay un cierto manejo de cultígenos (poroto y maíz), con sitios habitacionales a cielo abierto y en reparos rocosos, sin conformación de asentamientos como los de Copiapó.

Finalmente, un tercer sector sería Combarbalá/Choapa, el que al menos para Combarbalá ha sido interpretado como cazador-recolector (Méndez et al. 2009, Miranda 2006), y en Choapa se ha reconocido un modo de vida eminentemente móvil para estos grupos (Pavlovic 2004). En las comunidades de estos dos espacios no habría registro de domesticación de animales y se manejarían cultígenos únicamente de secano, tal como es la quinoa.

Estas diferencias en las formas de habitar de estos grupos a lo largo del NSA, implicarían que cada una de estas áreas tendría su propia dinámica social, la que articularía con las relaciones establecidas con áreas vecinas, como se observa claramente en los casos de Choapa y Copiapó a partir de sus tipos cerámicos (Castillo 1991, Niemeyer 1997a, Sanhueza et al. 2004).

De esta manera, bajo la "supuesta homogeneidad" que entrega la presencia de cerámica monocroma incisa/grabada/modelada, las pipas y los tembetás, los contextos arqueológicos sugieren formas muy distintas de habitar el mundo y diferenciales estrategias de apropiación de la naturaleza en el NSA, elevando un manto de duda de integrar toda esta variabilidad en un solo gran constructo denominado Complejo Cultural El Molle. Es más, si revisamos las tipologías de las piezas podemos reconocer otras tantas diferencias que hacen referencia a las formas cerámicas (bases apuntadas en Copiapó, motivo chevrón en Combarbalá-Choapa y que Sanhueza et al (2004), lo definen como Agrelo Calingasta), y los tipos de tembetás 
(tercera región de botón con aletas, Elqui-Limarí con abundante diversidad y Choapa de botón con aletas), aspecto que no abordaremos pues requiere un tratamiento bastante más detallado.

Esta variabilidad espacial debería también reconocerse a un nivel cronológico, pues dada la amplia extensión temporal de este período deberían esperarse transformaciones en las formas de vida de estas comunidades. Pensamos que el mejor ejemplo de la posibilidad de variación de estos dos ejes (espacial y temporal), lo constituye el sitio La Turquía (Iribarren 1958), el que con sus contextos con metalurgia en oro y plata, y su emplazamiento en un espacio precordillerano, marcan un quiebre con todo el registro arqueológico conocido para el PAT en la zona de Elqui-Limarí.

Esta situación implica una divergencia mayor a la planteada hasta el día de hoy en el NSA para el PAT, donde no sólo nos enfrentamos a una variabilidad intervalle, sino también posiblemente a una intravalle, como lo demostraría el caso de La Turquía en Limarí. Si esa variabilidad es producto de una variable cronológica o espacial es un tema que queda pendiente por los pocos datos disponibles.

\section{ReEVAluANdo El PERÍODO MEdio: COMPlejo CUltural LaS ÁNIMAS}

Reconocido inicialmente por Cornely (1956) como la etapa Arcaica de la Cultura Diaguita, los trabajos de Montané (1969) permitieron definir un período Medio (en adelante PM), representado por una entidad arqueológica particular, el Complejo Cultural Las Ánimas, el que se extendería espacialmente entre los valles de Copiapó y Limarí, y temporalmente entre 800-1200 d.C. (Castillo 1989). Su desarrollo y dinámica estaría muy imbricada con los procesos acaecidos en el NOA con el fenómeno La Aguada (Callegari 1997, Castillo 1989, Castillo et al. 1997).

Como sucede con la evidencia arqueológica disponible para el PAT, nos encontramos con que el registro es divergente a lo largo del NSA (Tabla 2), uniéndose básicamente por una tipología cerámica y una práctica funeraria de inhumación de cuerpos en asociación a camélidos. Tal variabilidad ha sido advertida recientemente por autores como Garrido (2008), quien ha planteado una reevaluación de los fundamentos de este Complejo.

Un primer ámbito de variación hace referencia nuevamente a la conformación de los espacios habitacionales, donde para el valle de Copiapó se han reconocido asentamientos con arquitectura en su variedad no 
fortificados y fortificados (Niemeyer 1997b), mientras que para espacios más meridionales, en particular para los valles de Elqui y Limarí se reconocen sólo sitios a cielo abierto, en particular conchales, sin que de momento haya registro de aldeas o asentamientos fortificados (Ampuero 1972-73, Castillo 1989, Cornely 1956, Iribarren 1970, Montané y Niemeyer 1960). Lamentablemente, para Huasco no se cuenta con información publicada que permita su discusión.

Un segundo ámbito de variabilidad se da en las prácticas funerarias, donde para Copiapó y Huasco nos encontramos con enterratorios en cementerios de túmulos y en pozos cilíndricos como ocurren en el sitio de La Puerta o en Chanchoquín Chico (Niemeyer 1997b, Kuzmanic 1988); mientras que para los valles de más al sur no hay registro de túmulos, correspondiendo los registros conocidos en Elqui únicamente a inhumaciones directas sobre los sedimentos acompañados por camélidos (Castillo 1984, Castillo et al. 1985, Castillo 1989, Cornely 1956), situación que al parecer sería similar en Limarí.

A estas diferencias en las formas de asentamiento y prácticas mortuorias se suman las divergencias en el registro bioarqueológico. Si bien es difícil efectuar comparaciones entre los sitios de Copiapó/Huasco con los conocidos para Elqui/Limarí dado sus emplazamientos diferenciales (interior $\mathrm{v} / \mathrm{s}$ costa respectivamente), un buen punto a considerar es el registro zooarqueológico que forma parte de los contextos funerarios Ánimas.

Para la primera zona es factible pensar en la presencia de Llama, tanto por su registro en tiempos previos (PAT), como por la posible presencia de corrales $^{2}$ (ver Niemeyer 1997b); mientras que el segundo sector, en particular Elqui, presenta una realidad muy distinta, pues los recientes análisis del contexto zooarqueológico del sitio Plaza de Coquimbo indica una presencia exclusiva de Guanaco (Lama guanicoe) (Becker y Cartajena 2005).

Las diferencias entre ambos espacios se reiteran con la alfarería, pues mientras para Copiapó/Huasco se representan únicamente los tipos Ánimas I y II (Cantarutti y Solervicens 2005, Niemeyer 1997b, Garrido 2008), en Elqui/Limarí hay una mayor representación del tipo Ánimas III (Cantarutti y Solervicens 2005, Garrido 2008). También es sólo en la primera zona donde se reconoce el tipo La Puerta (Iribarren 1969). 


\begin{tabular}{|c|c|c|c|c|c|c|}
\hline & $\begin{array}{l}\text { Tipos de } \\
\text { Asentamientos }\end{array}$ & \begin{tabular}{|l|} 
Tipos de \\
Enterratorios
\end{tabular} & \begin{tabular}{|l|} 
Tipos de \\
Camélidos \\
\end{tabular} & $\begin{array}{l}\text { Tipos de } \\
\text { Cultígenos }\end{array}$ & Otros & $\begin{array}{l}\text { Referencias } \\
\text { Bibliográficas }\end{array}$ \\
\hline $\begin{array}{l}\text { Valle de } \\
\text { Copiapó }\end{array}$ & $\begin{array}{l}\text { Aldeas } \\
\text { Sitios } \\
\text { Fortificados }\end{array}$ & $\begin{array}{l}\text { Túmulos } \\
\text { Pozos }\end{array}$ & Llamas & & \begin{tabular}{|l|} 
Predominio \\
Tipos \\
Animas I \\
y II
\end{tabular} & $\begin{array}{l}\text { Niemeyer } 1997 \mathrm{~b} \\
\text { Garrido } 2008\end{array}$ \\
\hline $\begin{array}{l}\text { Valle de } \\
\text { Huasco }\end{array}$ & Sin información & Túmulos & $\begin{array}{l}\text { Sin } \\
\text { información }\end{array}$ & $\begin{array}{l}\text { Sin } \\
\text { información }\end{array}$ & \begin{tabular}{|l|} 
Predominio \\
Tipos \\
Animas I \\
y II
\end{tabular} & Kuzmanic 1988 \\
\hline $\begin{array}{l}\text { Valle de } \\
\text { Elqui }\end{array}$ & $\begin{array}{l}\text { Sitios a cielo } \\
\text { abierto/ } \\
\text { conchales }\end{array}$ & Simples & Guanaco & $\begin{array}{l}\text { Sin } \\
\text { información }\end{array}$ & $\begin{array}{l}\text { Predominio } \\
\text { Tipo } \\
\text { Animas III }\end{array}$ & $\begin{array}{l}\text { Becker y Cartajena } \\
2005 \\
\text { Cantarutti y } \\
\text { Solervicens } 2005 \\
\text { Castillo } \text { et al. } 1985 \\
\text { Castillo } 1989 \\
\text { Cornely } 1956 \\
\end{array}$ \\
\hline $\begin{array}{l}\text { Valle de } \\
\text { Limarí }\end{array}$ & $\begin{array}{l}\text { Sitios a cielo } \\
\text { abierto/ } \\
\text { conchales }\end{array}$ & Simples & Guanaco & $\begin{array}{l}\text { Sin } \\
\text { información }\end{array}$ & $\begin{array}{l}\text { Predominio } \\
\text { Tipo } \\
\text { Animas III }\end{array}$ & $\begin{array}{l}\text { Cantarutti y } \\
\text { Solervicens } 2005 \\
\text { Cornely } 1956 \\
\text { Iribarren } 1970 \\
\text { Montané y } \\
\text { Niemeyer } 1960 \\
\end{array}$ \\
\hline $\begin{array}{l}\text { Valle de } \\
\text { Com- } \\
\text { barbalá }\end{array}$ & Ausencia & Ausencia & Ausencia & Ausencia & Ausencia & $\begin{array}{l}\text { Iribarren } 1973 \\
\text { Méndez y Jackson } \\
2008\end{array}$ \\
\hline $\begin{array}{l}\text { Valle de } \\
\text { Choapa }\end{array}$ & Ausencia & Ausencia & Ausencia & Ausencia & Ausencia & $\begin{array}{l}\text { Massone y Jackson } \\
1994 \\
\text { Rodríguez et al. } \\
1996,2000 \\
\end{array}$ \\
\hline
\end{tabular}

Tabla 2: Características de los contextos arqueológicos del periodo Medio en el Norte Semiárido.

Table 2: Characteristics of archaeological contexts of Middle Pottery period in the Semiarid North of Chile

Esta revisión de la evidencia contextual vuelve a mostrar una importante diferencia en los contextos arqueológicos del NSA, con una separación entre Copiapó/Huasco y los valles más meridionales. Mientras la primera zona presenta un modo de vida con aldeas (al menos en Copiapó), con asentamientos fortificados y no fortificados, asociados a enterratorios en túmulos y camélidos domesticados, en Elqui/Limarí no se da reconocen estos rasgos, sugiriéndose, por ende, un patrón de asentamiento disperso, enterratorios simples y camélidos silvestres (al menos en Elqui). Otra diferenciación ocurre a nivel de alfarería con frecuencias diferenciales para los tipos Ánimas I, II y III.

En esta lógica, volvemos a agrupar Elqui con Limarí, pues no obstante las diferencias en la cantidad de información para uno y otro valle, ambos espacios comparten tres de los cuatro rasgos en comparación, siendo la única 
excepción el tema de los camélidos, producto de una falta de información al respecto. No obstante dada la situación de Elqui, esperaríamos también un registro únicamente de guanacos.

Esta separación se complementa cuando incluimos como un tercer espacio el área de Combarbalá/Choapa, zona donde no hay registro de ocupaciones asignadas al Complejo Cultural Las Ánimas, no obstante la alta intensidad de investigación en ambas localidades (Castillo 1991, Iribarren 1973, Massone y Jackson 1994, Méndez y Jackson 2008, Rodríguez et al. 1996, 2000); conociéndose sólo un par de fragmentos recuperados en Los Vilos (Massone y Jackson 1994), sin que a partir de ellos sea posible postular que Ánimas ocupó el Choapa, ni menos que exista un período Medio asignado a esta entidad, no obstante las propuestas de Morello (1997) que fueron en su momento críticadas (Troncoso 1999-2000).

De esta manera, encontramos que el registro arqueológico establece durante el PM una nueva segregación tripartita en el NSA: por un lado, Copiapó-Huasco con un Complejo Ánimas representado por enterratorios de túmulos, animales domesticados y poblados fortificados y no fortificados; por otro, Elqui-Limarí con un registro completamente diferente donde están ausente las aldeas, los túmulos y los animales domesticados sugiriendo unas formas de vida completamente distintas a las de la Tercera Región; y finalmente Combarbalá-Choapa, con una ausencia de este Complejo. No obstante la homologación que establece la inhumación con camélidos en estos lugares, realmente se definen dos espacios con formas de vida distintos, y un tercero sin presencia de los elementos propios este período, reiterándose la organización tripartita reconocida durante el PAT.

\section{ReEVAluando el PERÍODo INTERMEdio TARDÍO: CUlturas Copiapó y Diaguita}

La conformación del período Intermedio Tardío (en adelante PIT) en el NSA es quizás el momento donde se observa de manera más clara las diferencias en los desarrollos culturales en esta zona. Ello, porque se ha reconocido la existencia de dos conjuntos culturales, por un lado, la Cultura Copiapó, que se distribuye por los valles de Copiapó y Huasco entre los años 1100 a 1450 d.C. aproximadamente (Castillo 1997, Gaete y Cervellino 2000), y por otro, la Cultura Diaguita, ubicada entre Elqui y Choapa en el lapso cronológico del 1000 a 1450 d.C. (Ampuero 1989, 1994, Troncoso 1999). 
Esta diferenciación cultural por si da cuenta de la segregación nuevamente de la zona Copiapó-Huasco de la realidad existente más al Sur, repitiendo la situación vista desde el PAT. Sin embargo, las otras dos segregaciones reconocidas en tiempos previos, Elqui/Limarí de Combarbalá/ Choapa, no son tan simples de detectar, pues las investigaciones efectuadas en la zona de Limarí y Combarbalá son bastante escasas para el PIT, situación muy diferente de lo que sucede para Elqui y Choapa, por lo que es complejo explorar las divergencias en las formas de vida y maneras de habitar de estas comunidades.

Sin embargo, hay tres aspectos que sugieren una diferenciación entre estas dos subáreas. Primero, a nivel de prácticas mortuorias, hay únicamente enterratorios en cistas en Elqui-Limarí, en oposición a inhumaciones directas en Combarbalá-Choapa. Segundo, la casi total ausencia de metalurgia para esta última zona en comparación a los registros conocidos en Elqui y Limarí (Iribarren 1973, Latorre y López 2011, Troncoso 1999, 2004). Tercero, la variabilidad de los patrones decorativos reconocidos por González (2001, 2004a, 2004b), tanto para el período Intermedio tardío como Tardío, que muestran una diferencia entre los tipos de diseño y patrones de simetría identificados en Elqui en comparación con aquellos de Choapa. Sin embargo, sólo nuevas investigaciones podrán dar mayores luces sobre posibles diferenciaciones entre estos espacios

\section{REEVALUANDO EL PERÍODO TARDÍO}

El período Tardío (en adelante PT) se define por la incorporación del NSA al Tawantinsuyu, y se extiende desde ca. 1450 d.C. hasta los inicios de la conquista hispánica de este territorio. Si bien podría pensarse que en este momento no son mayormente aplicables las diferencias reconocidas previamente debido a la intromisión de un estado que homogeneiza una realidad, el cúmulo de nuevas investigaciones realizadas en las dos últimas décadas han transformado y complejizado el panorama que se tenía para este momento. Pensamos que es posible reconocer nuevamente tres sectores con dinámicas de ocupación Inca diferencial, más allá de la homogeneidad que establece el trazado del camino y la presencia de tambos asociados a éstos y que han sido descritos por Niemeyer (1986) y Stehberg (1995), entre otros.

Para Copiapó/Huasco nos encontramos con que, más allá de las tipologías e instalaciones arquitectónicas construidas, la lógica de ocupación y anexión de este espacio descansó en la agencia de comunidades Diaguita incaizadas que incorporaron este territorio al Tawantinsuyu (Castillo 
1997). En contraposición, para Elqui/Limarí, el proceso de anexión habría descansado en la participación de comunidades incaizadas foráneas al NSA (Ampuero e Hidalgo 1975, Cantarutti 2002, Cantarutti y Mera 2004, Cornely 1956), reproduciéndose en contextos con piezas alóctonas y una variabilidad no reconocida de momento para otros espacios de la región. Esta situación se reproduce en altas cantidades de vasijas con formas y/o decoraciones incaicas en la zona (p.e. Huana. Fundo Coquimbo, Estadio Fiscal de Ovalle, Altovalsol, entre otros).

Combarbalá/Choapa constituiría un tercer sector con una dinámica diferente, pues los cambios que acaecen durante el PT no se basan en la incorporación de materialidades incaicas por las comunidades Diaguita, sino más bien descansan en transformaciones y ajustes de los conjuntos alfareros (y contextos) locales, los que han sido ampliamente descritos para el valle de Choapa (Troncoso 2004, Troncoso et al. 2004, Pavlovic et al. 2006), y se pueden reconocer también en Combarbalá (Iribarren 1973). Se caracterizan estos contextos por una abundancia de figurillas de arcilla, alfarería adscribibles a los tipos Diaguita Cuarto Estilo y Diaguita Huana (sensu Pavlovic et al. 2006), correspondientes a grandes contenedores que Iribarren (1973), asocia al tipo Punta Brava, y una gran cantidad de fragmentería del tipo Diaguita Policromo (sensu Pavlovic et al. 2006), principalmente del Estilo Clásico.

En particular, las características de los contextos del Choapa nos han llevado a sugerir que este espacio habría sido anexado al Tawantinsuyu por poblaciones Diaguita incaizadas de tierras más septentrionales (Elqui o Limarí) (Troncoso et al. 2008b), pues a los sutiles cambios que se observan en la cultura material de los grupos locales se suma el hecho que en el principal asentamiento incaico del área, Loma Los Brujos (Becker et al. 2004, Troncoso 2004), la casi totalidad del contexto remite a alfarería Diaguita-Inca más que Inca. Este hecho es coherente con la visión clásica que entendió al Choapa como una zona de baja presencia incaica, pues si bien se dan transformaciones significativas en los contextos locales durante el PT, hay una escasez de piezas incaicas en el área. Los contextos descritos por Iribarren (1973) para Combarbalá, reiteramos, sugieren una situación similar.

Estos antecedentes, por tanto, muestran que la tripartición reconocida previamente se reproduce durante el Tardío en el NSA a partir delas lógicas que guiaron la anexión de esta región al Tawantinsuyu. Es así, como en Copiapó y Huasco, la incorporación de este territorio al Inca estuvo mediatizada 
por comunidades Diaguita-Incaizados; en Elqui y Limarí, en cambio, fue agenciada por grupos foráneos al NSA, mientras que Combarbalá y Choapa lo fue por otras comunidades Diaguita-Incaizadas. Pensamos que este hecho podría ser una línea de evidencia indirecta que fundamentase la separación durante el PIT de Elqui/Limarí de Combarbalá/Choapa, pues como es sabido la ocupación del Tawansinsuyu se ajusta a las particularidades de cada uno de esos espacios, reconociendo tal variabilidad y actuando a partir de ella (p.e. D’Altroy 2003, Hyslop 1990).

\section{DISCUSIÓN: HISTORIA, SABERES Y PRÁCTICAS EN EL DESARROLLO DE}

\section{LAS COMUNIDADES ALFARERAS DEL NORTE SEMIARIDO}

A partir de la revisión de la información publicada hemos esbozado una reevaluación de los períodos Alfarero Temprano, Medio, Intermedio Tardío y Tardío en el NSA, discutiendo los datos disponibles en pos de aproximarnos a reconocer diferencias en las maneras de habitar y formas de vida de estas comunidades. Si bien la información es desigual entre los valles existiendo sesgos que no pueden ser obviados entre un área y otra, el conjunto de trabajos arqueológicos efectuados a lo largo de décadas y el registro conocido es lo suficientemente significativo como para proponer a estas diferencias como válidas. De hecho, es sobre este corpus de información que se han establecido las principales síntesis sobre la prehistoria local.

Nuestra revisión de las características del registro arqueológico en cada uno de los valles del NSA, ratifica la existencia de una importante heterogeneidad, variabilidad que traspasa las reconocidas diferencias tipológicas en la cultura material, para comprender diferencias en los modos de habitar y formas de vida de estas comunidades, las que en última instancia hacen referencia a diferentes niveles de complejidad entre uno y otro espacio.

Lo interesante de este reconocimiento es que permite segregar a lo largo del período Alfarero tres áreas diferentes, una septentrional definida por los valles de Copiapó y Huasco; otra central que comprende los valles de Elqui y Limarí; y una meridional que abarca Combarbalá y Choapa. Esta diferenciación que se reconoce en el PAT, se reproduce y mantiene en el PM, posiblemente se expande hasta el PIT y vuelve a cristalizar en el PT, dando cuenta de un proceso histórico diferencial para cada uno de estos espacios, no obstante su incorporación dentro de categorías generales como Complejo Cultural El Molle, Complejo Las Ánimas y Cultura Diaguita y Copiapó. 
Agrupados bajo un criterio tipológico de cultura material, estas entidades como constructos homogéneos al interior del NSA no dan cuenta de la variabilidad a nivel sociológico que se da entre las ocupaciones de cada uno de estos sectores, surgiendo la duda necesaria sobre si estas agrupaciones deben mantenerse como totalidades en atención a un criterio tipología $=$ cultura $=$ formas de vida y modos de habitar, o más bien segregarse a partir de sus dinámicas diferenciales. Sabiendo lo compleja que es tal discusión y la necesidad de mayores estudios en el área, nuestra opción es priorizar un enfoque centrado en los aspectos espaciales y temporales, más que únicamente uno etnológico de culturas o complejos.

Es así como para el PAT las diferencias entre valles son importantes, haciendo casi imposible intentar agrupar en un mismo constructo sociológico los desarrollos de Copiapó con los de Elqui-Limarí, menos los de Combarbalá y Choapa. Para el PM la situación es bastante similar, más allá de las diferencias reconocidas y discutidas en los contextos, es significativa la divergencia en la intensidad de ocupación Ánimas en la región septentrional con la central. Más allá de los sesgos propios a la ausencia de prospecciones sistemáticas en Elqui y Limarí, la verdad es que luego de tantas décadas de excavaciones de cementerios y tumbas, es factible pensar en un rango de ocupación efímero Ánimas en este espacio, situación que ha sido nublada por la riqueza del cementerio Plaza de Coquimbo. Al respecto, Garrido (2008), recientemente propuso también esta segregación Ánimas entre los dos sectores a partir de una revisión diferente de la evidencia aquí propuesta.

Es así como el PM se ve representado por intensidades de ocupación diferencial en el sector septentrional y central del NSA, evidenciado en la mayor cantidad y amplitud del registro arqueológico identificado para Ánimas en Copiapó v/s Elqui; las que se reproducen en diferencias en formas de habitar. En esa línea, mostramos nuestro desacuerdo con Cantarutti y Solervicens (2005), para quienes el conocimiento actual de Ánimas nos permite hablar solamente de un complejo de pucos. Creemos que la evidencia, aunque no abundante, da para más; el problema es que para este espacio central simplemente la evidencia es escasa producto de lo efímera de la ocupación Ánimas y la ausencia de investigaciones areales sistemáticas.

Es para el PIT donde la situación es algo más compleja. Por un lado, hay una claridad que se debe a la separación de dos entidades culturales en el área: Copiapó y Diaguita. Por otro, hay poca luz en relación a la separación entre el sector central y meridional del NSA, en particular, Limarí y 
Combarbalá, producto de la escasa investigación que impide establecer una buena comparación.

Para lo que es la separación Copiapó v/s Diaguita, la segregación viene a marcar las diferencias que se observaban ya desde el PAT de los valles de Copiapó y Huasco con el área central del NSA. En cambio, la separación entre el sector central y meridional del NSA se basa sólo en los datos que se tienen en la actualidad que permiten comparar de manera clara a Choapa y Elqui, sin que se pueda profundizar la relación Limarí-Combarbalá, pero que sin embargo, dado los antecedentes de tiempos previos (PAT y PM), sería esperable que se reiterase, como lo sugiere también la dinámica del período Tardío.

Este conjunto de situaciones nos pone ante una pregunta compleja, ¿cómo podemos explicar estas diferencias que se dan en la secuencia alfarera del NSA no obstante las existencia de similitudes que se reproducen en la cultura material entre estos distintos espacios en cada momento del período alfarero?. Los estudios efectuados en la década de los 60 y 70 plantearon como fundamento del cambio cultural el recambio poblacional y la fusión entre distintas poblaciones (p.e. Cornely 1956, Munizaga 1972-73). Para ello descansaron en variaciones en los conjuntos bioantropológicos que fundamentarían la existencia de distintas "razas" a lo largo de la secuencia.

A nuestro entender esta hipótesis es criticable por varias razones. Primero, todas ellas están al amparo de un modelo histórico-cultural en el que las variaciones bioantropológicas eran sinónimos de variación racial o poblacional (biotipología=cronología); sin embargo, en la actualidad sabemos que estas variaciones no son necesariamente producto de grupos distintos, sino que pueden responder a modos de vida diferentes.

Segundo, tales análisis no reconocieron la variable cronológica, por lo que no sólo se obvió el proceso histórico, sino que se desconocía a que momento específico del período en cuestión correspondían los cuerpos analizados, por lo que las relaciones causales podrían ser diferentes a las clásicamente mencionadas: en vez de ser el cambio biológico producto de nuevas poblaciones, podría darse que los cambios en las formas de vida llevasen a cambios biológicos. Tercero, hoy en día, tal hipótesis no explica la variabilidad que hemos reconocido durante el período alfarero en el NSA.

Proponemos que la explicación de esta variabilidad/homogeneidad en el NSA viene dada por aspectos muy diferentes; en particular, y retomando las proposiciones que hace años establecieron otros autores para la zona 
central de Chile (Falabella 1994, Thomas y Massone 1994), creemos que ellas son producto de la expansión de elementos ideacionales (flujo de ideas) a lo largo del NSA en distintos momentos del tiempo y que originan conjuntos materiales similares, no obstante las divergencias en los modos de vida.

Proponemos que este flujo de ideas se habría expandido a lo largo del área en diferentes épocas, asociándose a saberes y prácticas específicas que se objetivan en la cultura material (sensu Tilley 2008), pero articulando con los devenires históricos propios a cada uno de los espacios definidos. Este proceso habría ocurrido a tres escalas diferentes, generando homogeneidades y diferencias, las que no implican una homologación en las formas de vida y modos de habitar de las comunidades que habitaron este espacio (Figura 2).

En una primera escala, de nivel regional, proponemos la expansión de elementos ideacionales particulares a lo largo del NSA que genera una homogeneidad parcial en los contextos materiales producto de que ella se materializa en prácticas y saberes particulares, dando formación a lo que hoy conocemos como PAT, PM y PIT (Figura 2).

En este caso, el PAT representaría un primer flujo de ideas asociados a un saber que se reproduce en un sistema de comunicación visual alfarero basado en la aplicación de diseños básicamente no figurativos aplicados con las técnicas de incisión y grabados sobre formas mayormente restringidas. El compartir estas técnicas decorativas y diseños en el NSA daría cuenta de un lenguaje visual similar para el área más allá de las diferencias que se observan intervalles. Modelados, engobados y pintados serían también expresión de este sistema particular que se actualizaría y materializaría a partir de la producción y consumo de cerámica. 


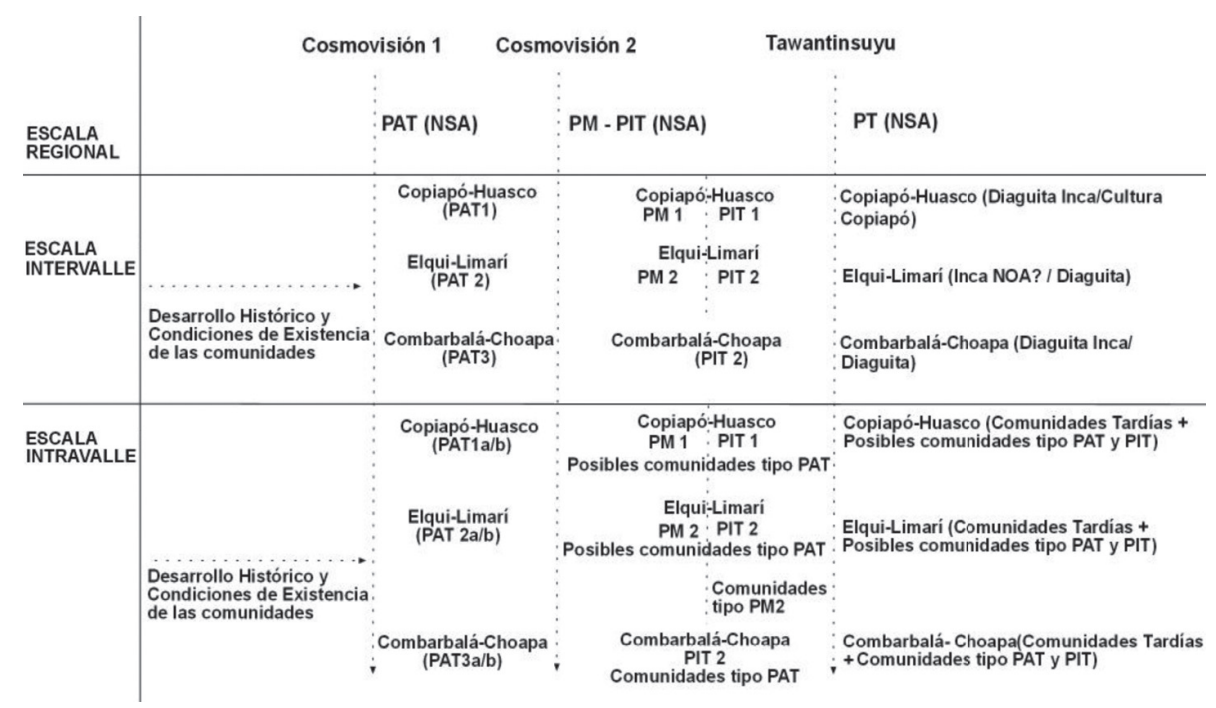

Figura 2: Modelo de interpretación del periodo alfarero en el norte semiárido chileno.

Figure 2: Model to interpret the pottery period in the Semiarid North of Chile.

Asociado a esta se daría también una tecnología particular de los cuerpos expresados en el uso y manejo de los tembetás en cuanto adorno corporal. De la misma manera, la exclusividad de las prácticas fumatorias materializadas en las pipas, sería otra práctica asociada con este flujo de ideas y sus saberes, siendo no sólo parte de la ergología de la ritualidad de este momento, sino también configurándola por medio del acto de fumar.

Estas similitudes, por tanto, no descansarían necesariamente en una forma de vida y modo de habitar similar, sino más bien en el compartir códigos visuales y materialidades que articulan con los aspectos ideacionales que orientan las prácticas de estas poblaciones, expresándose ellas en conductas particulares que entregan identidad a este momento del tiempo, estableciendo una articulación específica entre sujetos y objetos. Por bajo este nivel de homología se produciría una heterogeneidad en las formas de habitar y sistemas económicos que se expresaría en los ámbitos funcionales y económicos de elementos de la cultura material.

Para el PM sucedería algo similar. Nos enfrentaríamos a una transformación de estos elementos ideacionales que se expresaría en nuevas estrategias de comunicación que se materializan en la alfarería, codificándose la información ahora a partir de nuevos elementos iconográficos, una utilización (y posible significación) de otros colores opuestos a los de tiempos previos y la aparición de nuevas formas en la alfarería. Este último punto no 
es menor, pues implica que los códigos visuales materializados en las piezas articulan con un tipo de prácticas de consumo de alimentos y/o bebidas, completamente diferentes a las del lenguaje visual alfarero del PAT.

Junto a ellas, una nueva relación con los animales se materializaría, en particular con los camélidos, dada su inclusión en los contextos funerarios de estas comunidades, lo que implica una transformación en las conceptualizaciones referidas a la relacionalidad de los objetos que se incorporan en estos contextos. Y las prácticas de la ritualidad también se transformarían por medio de la aparición de la práctica de inhalación asociada no sólo a una nueva parafernalia material, sino también a otros códigos y mensajes visuales que se expresan en las espátulas.

Esta transformación de los elementos de la cultura material, por tanto, indicarían un cambio en aspectos comunicativos y simbólicos de estas poblaciones, las que en el fondo, se relacionarían con la expansión de saberes no presentes previamente y la generación de prácticas sociales novedosas (inhalación, consumo en vasijas abiertas, entre otros), deviniendo en una articulación diferente entre sujetos y objetos. Los cambios reconocidos en el PM serían coherentes con lo que sucede posteriormente en el PIT, sin que aún sea posible plantear un modelo de transición entre ambos momentos debido a la necesidad de datos más finos que los manejados en la actualidad.

Thomas y Salazar (2000), han planteado un modelo similar para pensar y analizar las transformaciones en el Norte Grande del país, enfatizando que los cambios se suceden antes que nada en la esfera de la ritualidad, que en los aspectos productivos. Para el NSA pensamos que la situación guarda cierta similitud con tal caso, pero no completamente, pues por debajo de las similitudes en la conformación de las materialidades, los sistemas de comunicación visual y la parafernalia ritual, se observan diferencias y matices en las ejecuciones al menos de los aspectos referidos a las prácticas mortuorias a partir de las diferentes estrategias de visibilidad implementadas durante el PAT y PM. No obstante ello, este flujo de ideas deviene en principios básicos que estructuran los lenguajes visuales plasmados en la alfarería, así como en las formas de practicar el consumo de alucinógenos, dos aspectos de importancia dentro en la ritualidad local.

Sin embargo, bajo esa supuesta homogeneidad, se establecerían una serie de diferencias entre los valles producto de los desarrollos históricos de cada uno de estos espacios, los que como hemos visto, expresan formas de vida y modos de habitar diferentes. Esta sería una segunda escala, inter-valle, que permitiría establecer la ya discutida organización tripartita del NSA. 
En otras palabras, este flujo de ideas, si bien implicaría ciertas prácticas y saberes específicos, no conllevaría una transformación necesaria de las formas de vida en todo este espacio, estableciéndose diferencias entre los valles producto de las historias locales y ritmos diferenciales de estas distintas localidades. De esta manera, se daría una relación bidireccional entre la adopción de estas ideas y las condiciones históricas de existencia de las comunidades que devienen en una cierta homogeneidad en la cultura material, una heterogeneidad en sus formas de vida (Figura 2).

Finalmente, a una escala intra-valle, proponemos que se establecería una diferenciación similar a la descrita recientemente. Dada la heterogeneidad y contemporaneidad en las formas de vida que se han podido reconocer hoy en el Choapa, y que es factible pensar que sucede en otros espacios, proponemos que la incorporación de estos elementos ideacionales articularían con las trayectorias de las distintas comunidades que habitan dentro de cada uno de estos valles, para generar diferencias entre ellas a partir de la adopción/ transformación/negación de estos aspectos superestructurales, proceso que seguramente debería ser coherente con las condiciones históricas y materiales de existencia de cada uno de estos grupos (Figura 2).

Este modelo pensamos entrega una herramienta heurística no sólo para interrogar el registro arqueológico, sino que posibilita comprender el porqué de la homogeneidad material que se da en el NSA durante el alfarero, pero también entender las razones en la variabilidad y heterogeneidad de las formas de vida, dando un rol central a los devenires históricos de cada espacio. En el fondo, ello explicaría más allá de la homogeneidad material que se da en Molle y Ánimas entre, por ejemplo, Copiapó y Elqui, las formas de habitar de estas comunidades serían completamente diferentes entre si.

La importancia de este devenir histórico es a nuestro entender central, pues ella sería el elemento que permitiría explicar la razón de la reiteración en la organización tripartita del registro en el NSA (Copiapó/Huasco; Elqui/Limarí y Combarbalá/Choapa), desde el PAT en adelante. A partir de las historias locales de cada una de estas áreas, se insertarían en una relación bidireccional con ella los nuevos elementos ideacionales particulares que aparecen. Surge entonces la pregunta, ¿Cuándo se da origen a estas divergencias?, es un tema que no es abordable a la luz de los actuales datos. Sabemos que están presentes ya en el PAT, por lo que es aventurable plantear que ellas podrían remitirse al menos al Arcaico Tardío, situación que deberá ser estudiada a futuro. 
Historia, saberes y prácticas se integran en un proceso que da un sentido a la prehistoria local marcando no sólo formas de habitar diferentes, sino ritmos distintos en cada uno de estos espacios, los que pueden ser discutidos a partir de las dataciones absolutas (tabla 3). Para el PAT se maneja una cantidad algo mayor a las 40 dataciones absolutas, tanto por termoluminiscencia como radiocarbono 14 . Si bien ambos son dos métodos diferenciales que fechan cosas distintas y con años bases divergentes, el ejercicio de comparar todas estas dataciones homologando sus años bases a 1950 entrega interesantes datos a la luz de las segregaciones propuestas.

\begin{tabular}{|c|c|c|c|c|c|}
\hline Período & Valle & Sitio & \begin{tabular}{|l|} 
Tipo de \\
Datación \\
\end{tabular} & Fechado & Referencia \\
\hline $\begin{array}{l}\text { Quebrada } \\
\text { Honda (AT) }\end{array}$ & Elqui & Tilgo & C14 & $1705+-95$ a.p. & Ampuero $1972-73$ \\
\hline $\begin{array}{l}\text { Quebrada } \\
\text { Honda (AT) }\end{array}$ & Limari & Valle El Encanto & $\mathrm{C} 14$ & $1710+-95$ a.p. & Ampuero 1972-73 \\
\hline PAT & \multirow[t]{9}{*}{ Copiapó } & Cueva de León & C14 & $1940+-50$ a.p. & Niemeyer 1997a \\
\hline PAT & & El Torín & C14 & $2050+-110$ a.p. & Niemeyer $1997 \mathrm{a}$ \\
\hline PAT & & El Torín & C14 & $1380+-80$ a.p. & Niemeyer $1997 \mathrm{a}$ \\
\hline PAT & & Carrizalillo Chico & $\mathrm{C} 14$ & 1470+-70 a.p. & Niemeyer 1997a \\
\hline PAT & & Carrizalillo Chico & TL & $400+-50$ d.C. & Niemeyer $1997 \mathrm{a}$ \\
\hline PAT & & Carrizalillo Chico & TL & $470+-100$ d.C. & Niemeyer $1997 \mathrm{a}$ \\
\hline PAT & & Carrizalillo Chico & TL & 480+-60 d.C. & Niemeyer 1997a \\
\hline PAT & & Carrizalillo Chico & TL & 500+-90 d.C. & Niemeyer 1997a \\
\hline PAT & & Cabra Atada & TL & 510+-50 d.C. & Niemeyer 1997a \\
\hline PAT & Huasco & Q. El Durazno & C14 & $1640+-90$ a.p. & $\begin{array}{l}\text { Iribarren y Niemeyer } \\
\text { 1956; Niemeyer } 1979\end{array}$ \\
\hline PAT & Elqui & Tilgo & $\mathrm{C} 14$ & 665 d.C. & Ampuero 1972-73 \\
\hline PAT & \multirow[t]{2}{*}{ Limarí } & $\begin{array}{l}\text { San Pedro Viejo de } \\
\text { Pichasca }\end{array}$ & C14 & $2670+-60$ a.p. & Rivera 1995 \\
\hline PAT & & $\begin{array}{l}\text { San Pedro Viejo de } \\
\text { Pichasca }\end{array}$ & C14 & $2565+-75$ a.p. & Rivera 1995 \\
\hline PAT & \multirow[t]{5}{*}{ Combarbalá } & Los Zorros & C14 & 1080 +-60 a.p. & Miranda 2006 \\
\hline PAT & & CBL020 & $\mathrm{C} 14$ & $1630+-40$ a.p. & Méndez et al. 2009 \\
\hline PAT & & \begin{tabular}{|l|} 
CLB020 \\
\end{tabular} & TL & 1190+-120 d.C. & \begin{tabular}{|l|} 
Méndez et al. 2009 \\
\end{tabular} \\
\hline PAT & & CBL061 & TL & 925-90 d.C. & Méndez et al. 2009 \\
\hline PAT & & La Olla & C14 & $1590+-120$ a.p. & Rivera y Cobo 1996 \\
\hline PAT & \multirow[t]{10}{*}{ Choapa } & Bato 2 & TL & 115+-160 d.C. & Sanhueza et al. 2004 \\
\hline PAT & & Batuco 2 & TL & 165+-190 d.C. & Becker 2003 \\
\hline PAT & & LV099B & TL & $170+-180$ d.C. & Sanhueza et al. 2004 \\
\hline PAT & & Bato 2 & TL & 185+-190 d.C. & Sanhueza et al. 2004 \\
\hline PAT & & $\begin{array}{l}\text { Parc. Alejandro } \\
\text { Mánquez } \\
\end{array}$ & TL & $270+-100$ d.C. & Rodríguez et al. 2000 \\
\hline PAT & & San Agustín 12 & TL & 275+-140 d.C. & Becker 2003 \\
\hline PAT & & Bato 2 & TL & $280+-170$ d.C. & Sanhueza et al. 2004 \\
\hline PAT & & San Agustin & TL & $300+-130$ d.C. & Becker 2003 \\
\hline PAT & & Bato 1 & $\mathrm{TL}$ & 390+-80 d.C. & Sanhueza et al. 2004 \\
\hline PAT & & $\begin{array}{l}\text { Parc. Alejandro } \\
\text { Mánquez }\end{array}$ & TL & $435+-100$ d.C. & Rodríguez et al. 2000 \\
\hline
\end{tabular}




\begin{tabular}{|c|c|c|c|c|c|}
\hline Período & Valle & Sitio & $\begin{array}{l}\text { Tipo de } \\
\text { Datación }\end{array}$ & Fechado & Referencia \\
\hline PAT & \multirow[t]{45}{*}{ Choapa } & Paso Hondo 1 & TL & 460+-190 d.C. & Becker 2003 \\
\hline PAT & & Bato 4 & $\mathrm{TL}$ & 475+-100 d.C. & Sanhueza et al. 2004 \\
\hline PAT & & Palmilla 2 & TL & 480+-110 d.C. & Becker 2003 \\
\hline PAT & & El Tome 1 & TL & 490+-110 d.C. & Becker 2003 \\
\hline PAT & & Ranqui 4 & TL & 515+-120 d.C. & Becker 2003 \\
\hline PAT & & LV163 & TL & $565+-250$ d.C. & Becker 2003 \\
\hline PAT & & El Tome 13 & $\mathrm{TL}$ & 590+-130 d.C. & Becker 2003 \\
\hline PAT & & Q. Chanchurria & $\mathrm{TL}$ & 590+-140 d.C. & Becker 2003 \\
\hline PAT & & Pichicavén 10 & TL & $600+-100$ d.C. & Rodríguez et al. 2000 \\
\hline PAT & & Loma Las Pircas & TL & 610+-140 d.C. & Rodríguez et al. 2000 \\
\hline PAT & & $\begin{array}{l}\text { Parcela Jacinto } \\
\text { Aguilera }\end{array}$ & $\mathrm{TL}$ & $670+-130$ d.C. & Rodríguez et al. 2000 \\
\hline PAT & & Bato 2 & TL & $745+-100$ d.C. & Sanhueza et al. 2004 \\
\hline PAT & & Los Mellizos & TL & 745+-130 d.C. & Troncoso et al. 2012 \\
\hline PAT & & Paso Hondo 1 & $\mathrm{TL}$ & 760+-120 d.C. & Becker 2003 \\
\hline PAT & & $\begin{array}{l}\text { Parcela Alejandro } \\
\text { Mánquez }\end{array}$ & $\mathrm{TL}$ & $795+-120$ d.C. & Troncoso 2011 \\
\hline PAT & & Pichicavén 1 & TL & $810+-110$ d.C. & Troncoso 2011 \\
\hline PAT & & Pichicavén 1 & TL & $810+-100$ d.C. & Troncoso 2011 \\
\hline PAT & & $\begin{array}{l}\text { Parcela Alejandro } \\
\text { Mánquez }\end{array}$ & $\mathrm{TL}$ & $825+-120$ d.C. & Troncoso 2011 \\
\hline PAT & & Pichicavén 1 & $\mathrm{TL}$ & 835+-95 d.C. & Troncoso 2011 \\
\hline PAT & & $\begin{array}{l}\text { Parcela Alejandro } \\
\text { Mánquez }\end{array}$ & $\mathrm{TL}$ & $845+-110$ d.C. & Troncoso 2011 \\
\hline PAT & & Los Mellizos & TL & $850+-90$ d.C. & Troncoso et al. 2012 \\
\hline PAT & & Ranqui 4 & TL & 855+-100 d.C. & Becker 2003 \\
\hline PAT & & Pichicavén 1 & $\mathrm{TL}$ & 855+-110 d.C. & Troncoso 2011 \\
\hline PAT & & $\begin{array}{l}\text { Parcela Alejandro } \\
\text { Mánquez }\end{array}$ & $\mathrm{TL}$ & $865+-110$ d.C. & Troncoso 2011 \\
\hline PAT & & Bato 1 & TL & 935+-105 d.C. & Sanhueza et al. 2004 \\
\hline PAT & & Manquehua 2 & TL & $860+-100$ d.C. & Becker 2003 \\
\hline PAT & & Pichicavén 1 & $\mathrm{TL}$ & $990+-100$ d.C. & Troncoso 2011 \\
\hline PAT & & Manquehua 4 & $\mathrm{TL}$ & 1010+-90 d.C. & Becker 2003 \\
\hline PAT & & LV065 & TL & 1065+-100 d.C. & Rodríguez et al. 2000 \\
\hline PAT & & LV065 & $\mathrm{TL}$ & 1070+-95 d.C. & Morello 1997 \\
\hline PAT & & El Tome 1 & $\mathrm{TL}$ & 1090+-90 d.C. & Morello 1997 \\
\hline PAT & & LV039 & TL & 1110+-50 d.C. & Becker 2003 \\
\hline PAT & & Cunlagua 6 & TL & 1155+-50 d.C. & Becker 2003 \\
\hline PAT & & Palmilla 2 & TL & 1165+-80 d.C. & Becker 2003 \\
\hline PAT & & El Tome 13 & TL & $1170+-80$ d.C. & Becker 2003 \\
\hline PAT & & Cunlagua 3 & $\mathrm{TL}$ & 1280+-70 d.C. & Becker 2003 \\
\hline PAT & & Camisas 6 & TL & 1280+-60 d.C. & Becker 2003 \\
\hline PAT & & El Tomé 8 & TL & 1310+-65 d.C. & Sanhueza et al. 2004 \\
\hline PAT & & Ranqui 4 & TL & 1420+-60 d.C. & Becker 2003 \\
\hline PAT & & Batuco 2 & TL & 1550+-30 d.C. & Becker 2003 \\
\hline PAT & & Los Mellizos & C14 & $790+-40$ a.p. & Troncoso et al. 2012 \\
\hline PAT & & Los Mellizos & C14 & $920+-30$ a.p. & Troncoso et al. 2012 \\
\hline PAT & & Quereo IV & C14 & 965+-60 d.C. & Núñez et al. 1984 \\
\hline PAT & & Pichicavén 1 & C14 & $1320+-35$ a.p. & Troncoso 2011 \\
\hline PAT & & Pichicavén 1 & $\mathrm{C} 14$ & $1110+-20$ a.p. & Troncoso 2011 \\
\hline
\end{tabular}




\begin{tabular}{|c|c|c|c|c|c|}
\hline Período & Valle & Sitio & $\begin{array}{l}\text { Tipo de } \\
\text { Datación }\end{array}$ & Fechado & Referencia \\
\hline PAT & \multirow[t]{4}{*}{ Choapa } & Pichicavén 1 & $\mathrm{C} 14$ & $1200+-40$ a.p. & Troncoso 2011 \\
\hline PAT & & Pichicavén 1 & $\mathrm{C} 14$ & $1490+-40$ a.p. & Troncoso 2011 \\
\hline PAT & & $\begin{array}{l}\text { Parcela Alejandro } \\
\text { Mánquez }\end{array}$ & C14 & $1030+-30$ a.p. & Troncoso 2011 \\
\hline PAT & & $\begin{array}{l}\text { Alero Paulino } \\
\text { González } \\
\end{array}$ & C14 & $840+-35$ a.p. & Troncoso 2011 \\
\hline PM & \multirow[t]{12}{*}{ Copiapó } & La Puerta & $\mathrm{TL}$ & $640+-150$ d.C. & Niemeyer 1997b \\
\hline PM & & La Puerta & TL & $680+-100$ d.C. & Niemeyer 1997b \\
\hline PM & & La Puerta & $\mathrm{TL}$ & 780+-60 d.C. & Niemeyer $1997 \mathrm{~b}$ \\
\hline PM & & La Puerta & $\mathrm{TL}$ & 790+-50 d.C. & Niemeyer 1997b \\
\hline PM & & La Puerta & $\mathrm{TL}$ & $850+-100$ d.C. & Niemeyer $1997 \mathrm{~b}$ \\
\hline PM & & La Puerta & $\mathrm{TL}$ & $860+-90$ d.C. & Niemeyer 1997b \\
\hline PM & & La Puerta & $\mathrm{TL}$ & $860+-120$ d.C. & Niemeyer $1997 \mathrm{~b}$ \\
\hline PM & & La Puerta & C14 & $1090+-50$ a.p. & Niemeyer 1997b \\
\hline PM & & La Puerta & C14 & $800+-50$ a.p. & Niemeyer $1997 \mathrm{~b}$ \\
\hline PM & & Quebrada Seca & $\mathrm{C} 14$ & $860+-60$ a.p. & Niemeyer 1997b \\
\hline PM & & Puntilla Blanca & C14 & $900+-50$ a.p. & Niemeyer 1997b \\
\hline PM & & Cabra Atada & $\mathrm{C} 14$ & $1100+-50$ a.p. & Niemeyer 1997b \\
\hline PM & \multirow[t]{2}{*}{ Elqui } & Plaza Coquimbo & C14 & $740+-60$ a.p. & Niemeyer 1997b \\
\hline PM & & Cia Teléfonos & $\mathrm{C} 14$ & $1045+-95$ a.p. & Ampuero 1972-73 \\
\hline PIT & \multirow[t]{12}{*}{ Copiapó } & Iglesia Colorada & $\mathrm{TL}$ & 1100+-70 d.C. & Castillo 1997 \\
\hline PIT & & Iglesia Colorada & $\mathrm{TL}$ & $1230+-90$ d.C. & Castillo 1997 \\
\hline PIT & & Punta Brava & $\mathrm{TL}$ & $1260+-50$ d.C. & Castillo 1997 \\
\hline PIT & & Iglesia Colorada & TL & 1300+-70 d.C. & Castillo 1997 \\
\hline PIT & & Los Molinos & $\mathrm{TL}$ & 1310+-70 d.C. & $\begin{array}{l}\text { Gaete y Cervellino } \\
2000\end{array}$ \\
\hline PIT & & Quebrada Cuestecilla & $\mathrm{TL}$ & 1310+-70 d.C. & $\begin{array}{l}\text { Gaete y Cervellino } \\
2000\end{array}$ \\
\hline PIT & & Iglesia Colorada & TL & 1315+-70 d.C. & Castillo 1997 \\
\hline PIT & & Quebrada Cuestecilla & $\mathrm{TL}$ & $1320+-40$ d.C. & $\begin{array}{l}\text { Gaete y Cervellino } \\
2000\end{array}$ \\
\hline PIT & & Los Molinos & $\mathrm{TL}$ & $1360+-65$ d.C. & $\begin{array}{l}\text { Gaete y Cervellino } \\
2000\end{array}$ \\
\hline PIT & & Los Fósiles & $\mathrm{TL}$ & $1360+-50$ d.C. & $\begin{array}{l}\text { Gaete y Cervellino } \\
2000\end{array}$ \\
\hline PIT & & Los Fósiles & $\mathrm{TL}$ & $1385+-50$ d.C. & $\begin{array}{l}\text { Gaete y Cervellino } \\
2000\end{array}$ \\
\hline PIT & & Los Fósiles & $\mathrm{TL}$ & $1395+-55$ d.C. & $\begin{array}{l}\text { Gaete y Cervellino } \\
2000\end{array}$ \\
\hline PIT & \multirow[t]{9}{*}{ Limarí } & Cogoti & TL & 975+-100 d.C. & Súarez et al. 1989 \\
\hline PIT & & San Julian & $\mathrm{TL}$ & 1055+-95 d.C. & \begin{tabular}{|l} 
Cantarutti y \\
Solervicens 2005 \\
\end{tabular} \\
\hline PIT & & San Julian & $\mathrm{TL}$ & 1075+-90 d.C. & $\begin{array}{l}\text { Cantarutti y } \\
\text { Solervicens } 2005\end{array}$ \\
\hline PIT & & San Julian & $\mathrm{TL}$ & $1120+-70$ d.C. & $\begin{array}{l}\text { Cantarutti y } \\
\text { Solervicens } 2005\end{array}$ \\
\hline PIT & & Cogoti & TL & 1130+-60 d.C. & Súarez et al. 1989 \\
\hline PIT & & Cogoti & TL & $1205+-80$ d.C. & Súarez et al. 1989 \\
\hline PIT & & San Julian & TL & 1300+-70 d.C. & Súarez et al. 1989 \\
\hline PIT & & Cogoti & $\mathrm{TL}$ & $1320+-100$ d.C. & Súarez et al. 1989 \\
\hline PIT & & Cogoti & $\mathrm{TL}$ & $1390+-80$ d.C. & Súarez et al. 1989 \\
\hline
\end{tabular}




\begin{tabular}{|c|c|c|c|c|c|}
\hline Período & Valle & Sitio & \begin{tabular}{|l|} 
Tipo de \\
Datación \\
\end{tabular} & Fechado & Referencia \\
\hline PIT & \multirow[t]{4}{*}{ Limarí } & Cogoti & TL & $1420+-50$ d.C. & Súarez et al. 1989 \\
\hline PIT & & Cogoti & $\mathrm{TL}$ & 1410+-60 d.C. & Súarez et al. 1989 \\
\hline PIT & & Cogoti & TL & 1430+-50 d.C. & Súarez et al. 1989 \\
\hline PIT & & San Julian & TL & 1490+-40 d.C. & Súarez et al. 1989 \\
\hline PIT & \multirow[t]{33}{*}{ Choapa } & Huintil 5 & TL & $850+-80$ d.C. & Troncoso 2001 \\
\hline PIT & & $\begin{array}{l}\text { Parcela Alejandro } \\
\text { Manquez }\end{array}$ & TL & $880+-110$ d.C. & Rodríguez et al. 2000 \\
\hline PIT & & \begin{tabular}{|l|} 
La Colonia 8 \\
\end{tabular} & TL & 920+-110 d.C. & Troncoso 2001 \\
\hline PIT & & Las Burras 5 & TL & 945+-100 d.C. & Troncoso 2001 \\
\hline PIT & & Independencia & TL & 970+-100 d.C. & Troncoso 2001 \\
\hline PIT & & Estadio Illapel & TL & 1030+-70 d.C. & Rodríguez et al. 2000 \\
\hline PIT & & Independencia & TL & 1030+-95 d.C. & Troncoso 2001 \\
\hline PIT & & $\begin{array}{l}\text { Parcela Alejandro } \\
\text { Manquez }\end{array}$ & TL & 1050+-80 d.C. & Rodríguez et al. 2000 \\
\hline PIT & & \begin{tabular}{|l|} 
Estadio \\
\end{tabular} & TL & 1070+-90 d.C. & Rodríguez et al. 2000 \\
\hline PIT & & Cesped 1 & TL & 1085+-95 d.C. & Troncoso 2001 \\
\hline PIT & & Estadio & TL & 1120+-80 d.C. & Rodríguez et al. 2000 \\
\hline PIT & & \begin{tabular}{|l|} 
Las Burras 7 \\
\end{tabular} & TL & 1150+-90 d.C. & Troncoso 2001 \\
\hline PIT & & LV039 & TL & $1160+-50$ d.C. & $\begin{array}{l}\text { Massone y Jackson } \\
1993\end{array}$ \\
\hline PIT & & Cesped 1 & TL & 1165+-50 d.C. & Troncoso 2001 \\
\hline PIT & & Huintil 5 & TL & $1165+-50$ d.C. & Rodríguez et al. 2000 \\
\hline PIT & & Cesped 1 & TL & 1175+-100 d.C. & Troncoso 2001 \\
\hline PIT & & \begin{tabular}{|l|} 
Sta Virginia 3 \\
\end{tabular} & TL & 1190+-70 d.C. & Troncoso 2001 \\
\hline PIT & & $\begin{array}{l}\text { Parcela Alejandro } \\
\text { Manquez }\end{array}$ & $\mathrm{TL}$ & 1210+-80 d.C. & Rodríguez et al. 2000 \\
\hline PIT & & LV181 & TL & $1240+-50$ d.C. & Troncoso 1999-2000 \\
\hline PIT & & Uruguay & TL & 1240+-70 d.C. & Troncoso 2001 \\
\hline PIT & & Lucuman 8 & TL & 1250+-70 d.C. & Troncoso 2001 \\
\hline PIT & & \begin{tabular}{|l|} 
Las Burras 2 \\
\end{tabular} & TL & 1255+-85 d.C. & Troncoso 2001 \\
\hline PIT & & Loma El Arenal & TL & 1255+-75 d.C. & Becker 2003 \\
\hline PIT & & Loma El Arenal & TL & 1270+-70 d.C. & Becker 2003 \\
\hline PIT & & Huintil 4 & TL & 1295+-50 d.C. & Rodríguez et al. 2000 \\
\hline PIT & & $\begin{array}{l}\text { Pisco Control } \\
\text { Salamanca }\end{array}$ & TL & $1350+-65$ d.C. & Becker 2003 \\
\hline PIT & & Chal Chal 3 & TL & 1360+-60 d.C. & Troncoso 2001 \\
\hline PIT & & \begin{tabular}{|l|} 
Lucuman 8 \\
\end{tabular} & TL & 1370+-60 d.C. & Troncoso 2001 \\
\hline PIT & & Césped 1 & C14 & 530+-25 a.p. & Troncoso 2011 \\
\hline PIT & & Loma El Arenal & C14 & 560+-25 a.p. & Troncoso 2011 \\
\hline PIT & & Loma El Arenal & C14 & $620+-25$ a.p. & Troncoso 2011 \\
\hline PIT & & Loma El Arenal & C14 & 500+-30 a.p. & Troncoso 2011 \\
\hline PIT & & Loma El Arenal & C14 & 560+-30 a.p. & Troncoso 2011 \\
\hline
\end{tabular}

Tabla 3: Dataciones absolutas publicadas para los periodos Alfarero Temprano,

Medio e Intermedio Tardio en el Norte Semiárido (AT=Arcaico Tardio, PAT= Periodo Alfarero Temprano, PM= Periodo Medio, PIT= Periodo Intermedio Tardio). Table 3: Absolutes dating to Early, Middle and Late Intermediate period in the Semiarid North of Chile $(A T=$ Late Archaic period, $P A T=$ Early Pottery Period, $P M=$ Middle Period, $P I T=$ Late Intermediate Period). 
Un primer resultado es el que las fechas PAT son más tempranas para los valles de Copiapó y Choapa, que Elqui y Limarí, lo que sin dudas debe ser un sesgo de la investigación. Sin embargo, los rangos cronológicos de la fase Quebrada Honda son muy próximos y se traslapan con las primeras ocupaciones PAT de otros espacios del NSA.

Lo anterior, unido a la organización tripartita del NSA lleva a pensar que: i) Quebrada Honda no es el origen del PAT en toda la región, sino que remite únicamente a Elqui-Limarí y ii) que posiblemente la adopción de la cerámica es un proceso con ritmos diferentes en cada uno de estos espacios. Sin embargo ello, es necesario seguir evaluando el desarrollo cronológico de la fase Quebrada Honda y la idoneidad de su existencia como constructo arqueológico.

Un segundo aspecto, proveniente más bien de las dataciones absolutas del valle de Choapa (Pavlovic 2005), y recientemente en Combarbalá (Méndez et al. 2009, Miranda 2006), es la pervivencia de grupos con cultura material PAT hasta los momentos finales de la época prehispánica, situación que no ha sido reconocida más al norte producto de la ausencia de amplias baterías de fechados y la asunción rígida de un criterio de tipología=cronología. Sin embargo, su realidad es factible y requiere ser evaluada con nuevas investigaciones que exploren la pervivencia de grupos poseedores de esta cultura material, así como la extensión cronológica de sus formas de vida hasta tiempos de la conquista.

Para el PM hemos registrado sólo 14 dataciones absolutas $\left(12{ }^{14} \mathrm{C}\right.$, 2 TL), en su mayoría de la zona de Copiapó, las que no entregan muchos aspectos para discutir, pero si pareciesen darse dos tendencias. Primero, una extensión temporal diferencial en la zona, con una cronología extensa en Copiapó (600 años), siendo contemporáneo con desarrollos PAT de Elqui/ Limarí y Combarbalá/Choapa; y una reducida extensión en Elqui (300 años), situación que puede ser un sesgo de la investigación o bien corresponder a un evento no tan extendido cronológicamente en la zona, lo que sería coherente con el escaso registro arqueológico Ánimas en tal área.

Esta situación se complica algo más al considerar la amplia batería de dataciones absolutas disponibles para la Cultura Diaguita, la que al menos en el valle del Choapa se remontan hacia el año 800 d.C, y con total seguridad al año 1000 d.C., siendo completamente contemporáneo con los desarrollos Ánimas en Elqui/Limarí. Si consideramos que las fechas Diaguita de Choapa deberían ser más tardías que en el sector central del NSA, estaríamos enfrentado al hecho de una coexistencia cronológica de 
comunidades con cultura material Diaguita y Ánimas no sólo al interior del NSA, sino también en los valles de Elqui y Limarí.

Todos estos resultados complejizan la realidad prehispánica del NSA, sugiriendo, como es esperable, la coexistencia de comunidades diferentes en un mismo espacio y tiempo, sin que se establezca necesariamente un proceso de reemplazo de unos grupos por otros. Es así como es factible pensar que hacia el año 1000 d.C. nos encontraríamos con comunidades con cultura material PAT, Ánimas y Diaguita coexistiendo en un mismo espacio, generando un escenario multicultural en un espacio donde antes no existía. Sobre esa base, se establecería también una diferenciación a lo largo de todo el NSA a partir de los ritmos diferenciales de cambios de las distintas comunidades.

La conformación de todo este proceso histórico de diferenciación en tres sectores diferentes se ratificaría al abordar la lógica de anexión incaica de este territorio, lógica en la que se implementan soluciones diferentes para cada espacio. Una ocupación mediada por contingentes incaizados ajenos al NSA en Elqui/Limarí, y otra por Diaguitas Incaizados posiblemente de ElquiLimarí en Copiapó/Huasco y Combarbalá/Choapa, con claras diferencias en las intensidades y lógicas de ocupación, así como en la incorporación de materialidades incaicas para ambos espacios.

Al respecto, el reconocimiento de esta dinámica para el PT implicaría que la anexión del NSA al Tawantinusyu debió haber sido realizada y operada desde el NOA, tal como lo avanzara hace unos años Castillo (1997). Sin embargo, a diferencia de su propuesta de un ingreso vía valle de Aconcagua, los datos de nuestra propuesta indican que la entrada habría sido a través de los valles de Elqui/Limarí ${ }^{3}$, situación ya sugerida por Cantarutti (2002), valles que se constituirían en las cabeceras de la ocupación incaica en el NSA. Desde estos espacios, por tanto, se habría coordinado y establecido la anexión y ocupación de los territorios vecinos por parte de grupos Diaguita, léase, al menos, Copiapó/Huasco y Combarbalá/Choapa.

Las diferencias registradas durante el PT y las hipótesis acerca de una penetración vía la zona central del NSA se ven confirmadas cuando evaluamos la organización territorial de la colonia española del Reino de Chile, en donde al menos se aprecia una segregación entre Elqui-Limarí y Combarbalá-Choapa (Pinto 1996, Urizar 2000). Por un lado Elqui-Limarì funcionan como una unidad, de la cual dependería Copiapó-Huasco, y por otro, Combarbalá-Choapa, dependiente del valle de Aconcagua, un espacio de ocupación incaica equivalente en significación al Limarì-Elqui. 
De esta manera, el momento terminal del desarrollo indígena en el NSA condensa todo el proceso histórico y divergencias reconocidas previamente, definiendo una dinámica particular de incorporación y alianzas de las comunidades locales con el Tawantinsuyu, respetando una segregación de este territorio en tres realidades diferentes que se expresaban ya hace al menos 1450 años antes de la llegada incaica a la región.

\section{Conclusiones}

A lo largo de este trabajo hemos revisado la evidencia arqueológica conocida para los distintos momentos del período alfarero en el NSA, proponiendo su reconceptualización a partir del reconocimiento de tres sectores de desarrollo histórico diferencial, los que por sobre una homogeneidad que se establece en la cultura material basada en el compartir elementos ideacionales comunes que se materializan en los objetos, saberes y prácticas comunes, se diferencian por sus formas de vida distintas y trayectorias históricas divergentes. Este modelo permitiría, por tanto, explicar tanto las similitudes como las diferencias reconocidas en los distintos sectores del NSA, apelando a una relación bidireccional entre lo ideacional (flujo de ideas) y lo material (condiciones históricas y materiales de existencia), reconociendo las sinergias de cada una de ellas en el proceso histórico.

En cierta medida este modelo recoge proposiciones que no sólo se han pensado para el Norte Grande, sino también para otros espacios, las que se han basado en la idea de expansión de sistemas simbólicos. En nuestro caso, hemos optado por una discusión a una escala intepretativa algo menor, hablando de elementos ideacionales y flujo de ideas, pues si bien ellas articulan necesariamente con un sistema simbólico, los datos actuales no permiten delinear de manera clara los elementos que constituyen tales sistemas. Por tal razón, lo que expresa la noción de flujo de ideas es ese ethos común que se reconoce por ejemplo, en las prácticas de uso de alucinógenos, en los lenguajes visuales de la alfarería, en las técnicas del cuerpo, las que en su trasfondo deberían dar cuenta de estos sistemas simbólicos que se deben develar tras el registro arqueológico. Sabemos que este modelo requiere nuevos y más datos para poder complejizarlo y afinar algunas de sus propuestas, pero por sobre eso, pensamos que los antecedentes con los que contamos hoy permiten al menos que sea propuesto.

Tres ramas surgen de este modelo que requieren ser exploradas mayormente. Una primera referida a contrastar estas diferencias en las 
características del arte rupestre en toda esta región, materialidad que en cuanto condensación de lo inmaterial debería reproducirlas. Lamentablemente la concentración de investigaciones en el extremo meridional del NSA, y el escaso conocimiento sobre las características de esta materialidad en la Tercera Región, dificultan establecer una clara comparación a partir de patrones cronológicos firmemente establecidos. Otra referida a las relaciones que se establecen entre estas diferencias espaciales con los entornos en los que se insertan estas comunidades, no pensando en un determinismo ambiental, sino en la necesaria relación dialéctica entre el habitar y el espacio, lo que sería otra línea de evidencia apuntando a esta tripartición. Una tercera asociada a reconocer las variabilidades temporales de este proceso, pues la escasa cantidad de dataciones absolutas fuera de los extremos del NSA hacen difícil aún poder abordar las transformaciones y ritmos de cambio que se dan dentro de cada uno de los períodos, y que como dijimos, podrían llegar a explicar también algunas diferencias dentro del registro como es por ejemplo, los contextos del sitio La Turquía.

Relevante se hace también el explorar las implicancias y relaciones que se establecen entre grupos humanos y materialidades. Si bien acá hemos usado un enfoque que relaciona materialidad con comunidades sociales y modos de vida (sin que ello implique necesariamente una identidad étnica), es necesario profundizar en tales relaciones para aclarar la dinámica social de la prehistoria local, más aún cuando nos enfrentamos con grupos que utilizan un conjunto material propio al PAT y mantienen un modo de vida móvil, pero cuya vida social se desarrolla pasado el año 1.000 d.C. en contemporaneidad con las comunidades Diaguita. Si bien hemos usado como nomenclatura los conceptos de grupos con cultura material tipo PAT, esto requiere una mayor exploración con el fin de mantener las etiquetas PAT/PM/PIT como indicadores cronológicos que acepten en su interior la coexistencia de diferentes tradiciones tecnológicas y modos de vida contemporáneamente, que es el fondo una de las propuestas de este paper.

En relación con lo anterior, es esencial a este modelo reevaluar las entidades que se han definido para el alfarero en el NSA, especialmente el Complejo Cultural El Molle y el Complejo Las Ánimas, pues sus expresiones fenoménicas en este territorio son bastante divergentes entre si. En esa línea, consideramos que un punto central es el reenfocar la investigación del alfarero en la zona más que a partir de Complejos o Culturas como unidad fundamental de análisis, a partir de un enfoque cronológico, reconociendo la coexistencia de variabilidad a nivel regional, local y temporal. Es así como proponemos trabajar con una visión histórica, no de períodos estancos 
segregados entre ellos, sino más bien de un desarrollo que se expande en el tiempo, en el que antes que cortes bruscos, se dan transformaciones, continuidades y variabilidades que van forjando las dinámicas socioculturales propias a cada valle, cada área y del NSA como un todo.

Sobre esta estrategia de trabajo y a partir del modelo aquí propuesto nacen un conjunto de nuevas interrogantes que esperamos se reproduzcan en nuevos problemas de investigación que permitan contribuir a profundizar el entendimiento de la historia prehispánica del NSA chileno.

Agradecimientos: a Lorena Sanhueza, Donald Jackson y los tres evaluadores anónimos de este artículo por sus sugerencias que ayudaron a mejorar este artículo. Al editor asociado de la revista Diego Salazar por sus comentarios y revisiones. Obviamente, los errores y omisiones siguen siendo nuestra responsabilidad. Este trabajo es parte del proyecto Fondecyt 1080360 .

\section{Notas}

1 Con el fin de reducir la cantidad de referencias bibliográficas del trabajo, al momento de citar datos específicos hemos optado, en los casos que se podía, a referenciar obras de carácter sintético que incluyesen esta información, antes que artículos específicos. Es así como, por ejemplo, para todo lo que es el registro arqueológico de Copiapó se privilegió citar el texto de Niemeyer et al. (1997), antes que los múltiples trabajos de estos autores publicados en revistas científicas o actas de congreso.

2 Una revisión inicial efectuada por C. Becker del material del sitio La Puerta indicaría la presencia de Llama en estos contextos (C. Becker, com. Pers. 2008)

3 A nuestro entender, el puntal de esta ocupación debería ser el valle de Limarí, pues los ricos contextos materiales que se expresan en el sitio Estadio Fiscal de Ovalle (Cantarutti 2002, Cantarutti y Mera 2004), no tienen parangón en Elqui.

\section{Bibliografía}

Ampuero, G., 1972-73. "Nuevos resultados de la arqueología del norte chico". Actas del VI Congreso Nacional de Arqueología Chilena, pp: 311-338. Universidad de Chile/Sociedad Chilena de Arqueología, Santiago.

1978. "Notas para el estudio de la Cultura Diaguita". Boletín del Museo Arqueológico de La Serena 16: 111-124.

_ 1989. "La Cultura Diaguita Chilena (1.200 a 1.470 d.C.)". En Culturas de Chile, Prehistoria, editado por J. Hidalgo, V. Schiappacasse, H. Niemeyer, C. Aldunate e I. Solimano, pp. 277-288. Editorial Andrés Bello, Santiago.

1994. Cultura Diaguita Chilena. Ministerio de Educación, Santiago.

Ampuero, G. y J. Hidalgo, 1975. "Estructura y proceso en la pre y protohistoria del Norte Chico de Chile". Chungara 5: 87-125. 
Ampuero, G. y M. Rivera, 1964. "Excavaciones en la quebrada El Encanto, Departamento de Ovalle (informe preliminar)". Actas del III Congreso Internacional de Arqueología Chilena, Arqueología de Chile central y áreas vecinas, pp: 207-218. Sociedad Chilena de Arqueología, Viña del Mar

— 1969. "Excavaciones en quebrada El Encanto, nuevas evidencias". Actas del $V$ Congreso Nacional de Arqueología Chilena, pp: 185-206. Museo Arqueológico La Serena/Sociedad Chilena de Arqueología, La Serena.

_ 1971. "Secuencia arqueológica del alero rocoso de San Pedro Viejo de Pichasca”. Boletín del Museo Arqueológico de La Serena 14:45-69.

_ 1972-73. "Síntesis interpretativa de la arqueología del Norte Chico". Actas del VI Congreso de Arqueología Chilena, pp: 339-344. Santiago

Ballereau, D. y H. Niemeyer, 1998. "Los sitios rupestres de la cuenca alta del río Illapel (Norte Chico, Chile)”. Chungara 28 (1-2): 319-352.

Belmar, C. y L. Quiroz, 2002. "Informe Arqueobotánico sitios El Bato: Análisis Carpológico”. En Informe Proyecto Impacto Ambiental Embalse El Bato. Manuscrito.

_ 2003 "Informe Arqueobotánico sitios arqueológicos del valle de Chalinga: Análisis Carpológico”. En: Informe final proyecto Fondecyt 1000039. Conicyt, Santiago.

Becker, C. 2003. Arqueología en el río Chalinga. Informe final proyecto Fondecyt 1000039. Conicyt, Santiago.

— 2004. "Animales que cuentan historias". Chungara, volumen especial, tomo II: 359-364.

Becker, C. e I. Cartajena. 2005. "Las ofrendas de camélidos en el cementerio de la plaza Coquimbo, una nueva mirada". Fondo de Apoyo a la Investigación Patrimonial, Informes, pp: 77-86.

Becker, C., J. Rodríguez, A. Troncoso, D. Pavlovic y P. Gonzalez. 2004. "Loma Los Brujos, las estructuras del Inca en Illapel". Fondo de Apoyo a la Investigación Patrimonial, Informes, pp: 65-71.

Biskupovic, M. 1985. “Excavación arqueológica en la parcela N²1 de Peñuelas, Coquimbo". Actas del IX Congreso Nacional de Arqueología Chilena, pp: 240-248. La Serena.

Biskupovic, M. y G. Ampuero 1991. "Excavación arqueológica en la parcela 24 de Peñuelas, Coquimbo, Chile". Actas del XI Congreso Nacional de Arqueología Chilena, tomo III: 41-48. Santiago. 
Cabello, G. 2005. Rostros que hablan, una propuesta estilistica para arte rupestre de Chalinga, IV región. Memoria para optar al título profesional de Arqueólogo. Departamento de Antropología, Universidad de Chile, Santiago.

2011. "De rostros a espacios compositivos: una propuesta estilística para el valle de Chalinga, Chile". Chungara 43(1): 25-36.

Callegari, A. 1997. "Interacción entre el valle de Copiapó y el centro norte del valle de Vinchina (La Rioja)”. Estudios Atacameños 14: 131-142.

Cantarutti, G., 2002. Estadio fiscal de Ovalle, redescubrimiento de un sitio Diaguita-Inca en el valle de Limarí. Memoria para optar el título de Arqueólogo. Departamento de Antropología, Universidad de Chile.

Cantarutti, G. y R. Mera. 2004. "Estadio Fiscal de Ovalle: redescubrimiento de un sitio Diaguita-Inca en el valle del Limarí”. Chungara, volumen especial, tomo II: $833-846$.

Cantarutti G y C. Solervicens, 2005. "Cultura Diaguita preincaica en el valle del Limarí: una aproximación a partir del estudio de colecciones cerámicas”. Actas del XVI Congreso Nacional de Arqueología Chilena, pp: 147-156. Tomé: Museo de Concepción/Sociedad Chilena de Arqueología

Castillo, G. 1984. "Un cementerio del Complejo Las Ánimas en Coquimbo, ejemplo de relaciones con San Pedro de Atacama”. Estudios Atacameños 7: 264-277.

_ 1986 "Sociedades agropecuarias tempranas y control de recursos en el ambiente semiárido de Chile”. Chungara 16-17:119-124.

__ 1989 "Agricultores y pescadores del Norte Chico: El Complejo Las Ánimas (800 a 1200 d.C.)". En Culturas de Chile, Prehistoria, editado por J. Hidalgo, V. Schiappacasse, H. Niemeyer, C. Aldunate e I. Solimano, pp. 265-276. Editorial Andrés Bello, Santiago.

— 1991. Desarrollo prehispánico en la hoya hidrográfica del río Choapa. Manuscrito

_ 1997. "Los períodos Intermedio Tardío y Tardío: desde la cultura Copiapó al dominio Inca”. En Culturas Prehistóricas de Copiapó, editado por H. Niemeyer, M. Cervellino y G. Castillo, pp: 163-282. Museo Regional de Atacama, Copiapó.

Castillo, G., H. Niemeyer y M. Cervellino. 1997. "Indicadores, alcances y perspectivas de influencias Aguada en el valle de Copiapó-Chile”. Shincal 6: 193-212. 
Castillo, G., M. Biskupovic y G. Cobo. 1985. "Un cementerio costero del Complejo Cultural Las Ánimas". Actas del IX Congreso Nacional de Arqueología Chilena, pp: 194-239. La Serena.

Cornejo, L. y L. Sanhueza 2003 "Coexistencia de cazadores recolectores y horticultores tempranos en la cordillera Andina de Chile Central”. Latin American Antiquity 14(4):389-407.

Cornely, F. 1956 Cultura Diaguita Chilena y Cultura El Molle. Editorial del Pacífico, Santiago.

_ 1958. "Cultura El Molle". Arqueología Chilena 4: 1-4

Criado, F., 1993. "Visibilidad e interpretación del registro arqueológico". Trabajos de Prehistoria 50: 39-56.

— 2000. "Walking about Lévi-Strauss, contributions to an Archaeology of thought". En Philosophy and Archaeological Practice, editado por C. Holtorf y H. Karlsson, pp: 277-304. Bricoleur Press, Goteborg.

D’Altroy, T. 2003. Los Incas. Ariel Editores, Barcelona.

Eerkens, J. 2003. "Residential mobility and pottery use in the western great basin”. Current Anthropology 44 (5): 728-738.

Falabella, F. 1994. "Dos puntas tiene el camino: antiguas relaciones trasandinas en el centro de Chile y Argentina". En La cordillera de Los Andes, ruta den encuentros, editado por el Museo Chileno de Arte Precolombino, pp: 39-48. Museo Chileno de Arte Precolombino, Santiago.

Garrido, F. 2008. El camélido sagrado y el hombre de los valles, una aproximación a la Cultura Copiapó y sus relaciones a partir de la alfarería. Memoria para optar al título profesional de Arqueólogo. Departamento de Antropología, Universidad de Chile, Santiago.

Gaete, N. y M. Cervellino. 2000. "Asentamientos habitacionales de la Cultura Copiapó en el río Jonquera, formativo del río Copiapó, región de Atacama, Chile”. Contribución Arqueológica 5, tomo II: 607-630.

Gallardo, F. 1990. Basuras en el cementerio. Memoria para optar al título de Licenciado en Arqueología, Universidad de Chile. Santiago.

González, P. 2001. "Estructura del arte, espacio e identidad: la cultura Diaguita en el valle de Illapel. Actas del IV Congreso Chileno de Antropología, tomo II: 1377-1382. Colegio de Antropologos de Chile, Santiago.

2004a. "Estilo, interacción y poder: arte visual Diaguita Inca en asentamientos habitacionales de valle de Illapel y del área Diaguita nuclear". Werken 5: 69-76. 
— 2004b. "Patrones decorativos y espacio: el arte visual Diaguita y su distribución en la cuenca del río Illapel” Chungara 36, vol. Especial 2: 767781.

Hyslop, J. 1990. Inka settlement planning. University of Texas Press, Texas.

Iribarren, J. 1958. "Nuevos hallazgos arqueológicos en el cementerio indígena de La Turquía-Hurtado". Arqueología Chilena 4: 13-40

_ 1969. "Culturas trasandinas en dos yacimientos del valle de Copiapó". Actas del V Congreso Nacional de Arqueología, pp: 135-152. La Serena.

— 1970. Arqueología y antecedentes históricos del valle del río Hurtado. Ediciones del Museo Arqueológico de La Serena, La Serena.

— 1973 "La arqueología en el departamento de Combarbalá (Provincia de Coquimbo, Chile)”. Boletín del Museo Arqueológico de la Serena 15:7-113.

Irribarren J. y H. Niemeyer, 1956. "Arqueología en el valle del Huasco, provincia de Atacama”. Revista Universitaria XL-XLI: 183-212

Jackson, D., 2005. "Camélidos en el arte rupestre de la cuenca hidrográfica del río Choapa, hacia una discusión de sus distinciones". Trabajo presentado en el V Congreso Nacional de Antropología, San Felipe.

Jackson, D., D. Artigas y G. Cabello, 2002. Trazos del Choapa, arte rupestre en la cuenca del río Choapa, una perspectiva macroespacial. Lom Impresores, Santiago.

Kuzmanic, I. 1988. "Un cementerio del período Medio en Chanchoquín Chico, Provincia de Huasco, III Región”. Publicación Ocasional 1, Museo Regional de Antofagasta.

Kuzmanic, I. y G. Castillo. 1986. "Estadio Arcaico en la costa del norte semiárido de Chile". Chungara 16/17: 89-94.

Labarca, R. 2008. "Análisis faunístico de los yacimientos de Las Terneras 1 y 2, sector La Coipa, Región de Atacama”. Informe de Estudio de Impacto Ambiental preparado para MAA Consultores. Santiago.

Latcham, R. 1928. La Prehistoria chilena. Sociedad Impresora y Litográfica Universo, Santiago.

— 1937. "Arqueología de los indios Diaguitas". Boletín del Museo Nacional de Historia Natural 16: 17-35.

Latorre, E. y P. López 2011. "Los metales en la cultura Diaguita Chilena (ca. 9001536 d.C.): Una aproximación metodológica e interpretativa”. Intersecciones en Antropología 12(2): 319-332. 
Massone, M. y D. Jackson 1994. "Asentamiento de explotación litoral del agroalfarero medio-tardío en la comuna de Los Vilos". Boletín del Museo Regional de la Araucanía 5: 9-18.

Méndez, C. y D. Jackson 2008. "La ocupación prehispánica de Combarbalá: una propuesta sintética”. Chungara Revista de Antropología Chilena 40(2): 5-17.

Méndez, C, D. Jackson y B. Ladrón de Guevara. 2004. “Cazadores recolectores tempranos al interior del semiárido: una visión exploratoria a partir de las distribuciones superficiales de los cursos fluviales de Pama y Combarbalá (Prov. de Limarí)". Anuario de la Universidad Internacional SEK 9:9-22.

Méndez, C., A. Troncoso, D. Jackson y D. Pavlovic. 2009. "Uso del espacio entre cazadores recolectores tardíos en espacios cordilleranos del norte semiarido de Chile". Intersecciones en Antropología 10: 313-326.

Miranda, C. 2006 "Evaluación de un contexto de caza y recolección en momentos tardíos: sitio Los Zorros, un alero rocoso al interior del Semiárido”. Werken 8: $25-41$.

Montané, J. 1969. "En torno a la cronología del Norte Chico". Actas del VI Congreso Nacional de Arqueología, pp: 167-183. La Serena.

Montané, J. y H. Niemeyer 1960. "Arqueología Diaguita en conchales de la costa". Boletín del Museo Arqueológico de La Serena 11: 53-75.

Morello, F. 1997. "Hallazgos y problemas de un sitio del período Alfarero Medio, LV-065 (Quereo Sur, Los Vilos)". Boletín de la Sociedad Chilena de Arqueología 24:24-27.

Munizaga, J. 1972-73. "Síntesis de la antropología física del norte chico". Actas del VI Congreso de Arqueología Chilena, pp: 345-351. Santiago.

Niemeyer, H. 1979. "Cultura El Molle en río Huasco, revisión y síntesis". Actas del VIII Congreso de Arqueología Chilena, pp: 295-320. Valdivia.

— 1986. "La ocupación inkaica en la cuenca alta del río Copiapó". Comechingonia, número especial, pp: 165-294.

— 1997a. "El período temprano del horizonte agroalfarero en Copiapó". En Culturas Prehistóricas de Copiapó, editado por H. Niemeyer, M. Cervellino y G. Castillo, pp: 39-60. Museo Regional de Atacama, Copiapó.

_ 1997b. "El período medio. Complejo Las Ánimas". En Culturas Prehistóricas de Copiapó, editado por H. Niemeyer, M. Cervellino y G. Castillo, pp: 115162. Museo Regional de Atacama, Copiapó. 
Niemeyer, H. y D. Ballereau. 1998. "Los petroglifos del cerro La Silla, región de Coquimbo”. Chungara 28 (1-2): 277-318.

Niemeyer, H., G. Castillo y M. Cervellino 1989 "Los primeros ceramistas del Norte Chico: Complejo El Molle (0 a 800 d. C.)”. En Culturas de Chile, Prehistoria, editado por J. Hidalgo, V. Schiappacasse, H. Niemeyer, C. Aldunate e I. Solimano, pp. 227-263. Editorial Andrés Bello, Santiago.

Niemeyer, H., M. Cervellino y G. Castillo. 1997. Culturas Prehistóricas de Copiapó. Museo Regional de Atacama, Copiapó.

Núñez, L., J. Varela, R. Casamiquela, y C. Villagrán, C., 1984. "Reconstitución multidisciplinada de la secuencia prehistórica de quebrada Quereo". Latín American Antiquity 5 (2): 99-118,

Pavlovic, D. 2004 "Dejando atrás la tierra de nadie: asentamientos, contextos y movilidad de las comunidades alfareras tempranas del Choapa". Werken 5:39-46.

Pavlovic, D., A. Troncoso, C. Becker, J. Rodriguez y P. González. 2006. "Escobillado, cuarto estilo y grandes contenedores: el conjunto alfarero Diaguita durante el período Inca en la Provincia del Choapa”. Actas del XVII Congreso Nacional de Arqueología Chilena, tomo I: 285-296. Valdivia.

Pinto, J. 1996 "La Población del Corregimiento de Quillota en el siglo XVIII". Valles 2: 13-28.

Politis, G., G. Martínez y M. Bonomo, 2001. "Alfarería temprana en sitios de cazadores-recolectores de la región Pampeana (Argentina)". Latin American Antiquity 12(2):167-181.

Rivera, M. 1995. "Recientes fechados de C-14 por AMS de muestras de porotos del alero San Pedro Viejo de Pichasca". Boletín de la Sociedad Chilena de Arqueología 21:27.

Rivera, M. y G. Ampuero. 1969. "Excavaciones en la quebrada El Encanto, nuevas evidencias". Actas del V Congreso Nacional de Arqueología, pp: 185206. La Serena.

Rivera, M. y G. Cobo 1996 "Excavaciones arqueológicas en Combarbalá: cuevas Flor del Valle y La Olla, Valle Hermoso". Boletín del Museo Arqueológico de la Serena 19:89-111.

Rodríguez, J., C. Becker, L. Solé, P. González y A. Troncoso, 1996. "Algunas reflexiones sobre las poblaciones prehispánicas tardías del río Illapel”. Valles Revista de Estudios Regionales 2:57-71. 
Rodríguez, J., A. Troncoso, C. Becker, P. González y D. Pavlovic 2000 "Ocupaciones prehispanas en la cuenca del río Illapel". Actas del XIV Congreso Nacional de Arqueología Chilena, tomo II: 331-342. Copiapó.

Sanhueza, L., D. Baudet, D. Jackson y L. Contreras 2004. "La Cultura Agrelo Calingasta en el Choapa". Werken 5: 47-52.

Schiappacasse, V. y H. Niemeyer 1986. "El Arcaico en el norte semiárido de Chile, un comentario". Chungara 16-17: 95-98.

Stehberg, R. 1995. Instalaciones incaicas en el norte y centro semiárido de Chile. Centro de Investigaciones Diego Barros Arana, DIBAM, Santiago.

Suárez, L.; L. Cornejo, A. Deza y A. Román 1989. "Primeros fechados absolutos para la cultura Diaguita”. Actas del XI Congreso Nacional de Arqueología Chilena, tomo III: 49-56. Santiago.

Thomas, C. y C. Massone. 1994. "El Complejo Cultural Aconcagua: una consideración desde un enfoque estructural”. Actas del II Taller de Arqueología de Chile Central. Disponible en http://www.geocities.com/ actas2taller/thomas.htm.

Thomas, C. y D. Salazar. 2000. "Huaris y llaucaces: un modelo representacional andino de dominación”. Diálogo Andino 19:85-110

Tilley, C. 2008. "Objectification”. En Handbook of material culture, editado por C. Tilley, W. Keane, S. Küchler, M. Rowlands y P. Spyer, pp: 61-73. Sage, Londres.

Troncoso, A. 1999. "La Cultura Diaguita en el valle de Illapel: una perspectiva exploratoria”. Revista Chungara 30 (2): 125-142.

— 1999-2000. "La Cultura Diaguita y el Período Intermedio Tardío en la costa de Los Vilos, Provincia del Choapa”. Revista Chilena de Antropología 15:4962.

— 2001. "La Cultura Diaguita en el 2001: Problemas y perspectivas desde el Choapa”. Actas del $4^{\circ}$ Congreso Chileno de Antropología, tomo I: 1351-1356. Santiago.

_ 2004. "Relaciones socio-culturales de producción, formas de pensamiento y ser en el mundo: un acercamiento a los períodos Intermedio Tardío y Tardío en la cuenca del río Choapa". Werken 5: 61-68

2009. "Formas, estilo y espacio en el arte rupestre de los valles de Illapel y Chalinga, Provincia del Choapa". Informe proyecto Fondecyt 1080360, año 1. Conicyt, Santiago. 
_ 2011. "Formas, estilo y espacio en el arte rupestre de los valles de Illapel y Chalinga, Provincia del Choapa”. Informe proyecto Fondecyt 1080360, año 3. Conicyt, Santiago.

2012. "Arte rupestre y camélidos en el norte semiárido de Chile: una discusión desde el valle de Choapa". Boletín del Museo Chileno de Arte Precolombino 71(1): 75-93.

Troncoso, A., D. Pavlovic, C. Becker, P. González y J. Rodríguez. 2004. "Césped 3, asentamiento del período Diaguita-Incaico sin cerámica Diaguita Fase III en el curso superior del río Illapel, IV región, Chile”. Chungara, volumen especial, tomo II: 893-906.

Troncoso, A.; F. Armstrong, F. Vergara, P. Urzua y P. Larach. 2008a. "Arte rupestre en el valle El Encanto: Hacia una reevaluación del sitio-tipo del Estilo Limarí”. Boletín del Museo Chileno de Arte Precolombino 13(2): 9-36.

Troncoso, A.; C. Becker, D. Pavlovic, P. González y J. Rodríguez. 2008b. "El Inca en el Choapa". En Informe proyecto Fondecyt 1040153, año 4. Conicyt, Santiago.

Troncoso, A., P. Larach, S. Alfaro, D. Pascual y D. Pavlovic. 2012. "Nuevos antecedentes para el período Alfarero Temprano en el valle del Choapa: el sitio Los Mellizos (cuenca superior del río Illapel). Actas del XVIII Congreso Nacional de Arqueología Chilena, pp: 30-319. Sociedad Chilena de Arqueología, Valparaíso.

Urizar, M. 2000. "Una revisión de la realidad étnica en el valle del río Choapa siglo XVII-XVIII y sus posibles conexiones con la población del periodo de contacto hispano-indigena”. Actas del XIV Congreso Nacional de Arqueología Chilena, tomo I: 133-143. Copiapó. 